\title{
A Comparative Study on Performance of Analysis Nudging and 3DVAR in Simulation of a Heavy Rainfall Event Using WRF Modeling System
}

\author{
Ashish Routray, ${ }^{1,2}$ Krishna K. Osuri, ${ }^{3}$ and Makarand A. Kulkarni ${ }^{4}$ \\ ${ }^{1}$ National Centre for Medium Range Weather Forecasting (NCMRWF), A-50, Sector 62, Noida 201 309, India \\ ${ }^{2}$ Environmental Modeling Center, National Centers for Environmental Prediction (NCEP), 5200 Auth Road, Camp Springs, \\ MD 20746, USA \\ ${ }^{3}$ Centre for Atmospheric Sciences, Indian Institute of Technology, Delhi, New Delhi, Hauz Khas 110 016, India \\ ${ }^{4}$ Statistical Research, Skymet Weather Services, Noida, 201 307, India \\ Correspondence should be addressed to Ashish Routray, ashishroutray.iitd@gmail.com
}

Received 1 April 2012; Accepted 29 May 2012

Academic Editors: L.-T. Hsieh, K. Nakamura, Z. Pu, F. Tao, and D.-Y. Wang

Copyright ( 2012 Ashish Routray et al. This is an open access article distributed under the Creative Commons Attribution License, which permits unrestricted use, distribution, and reproduction in any medium, provided the original work is properly cited.

The present study focuses on the performance-based comparison of simulations carried out using nudging (NUD) technique and three-dimensional variational (3DVAR) data assimilation system (3DV) of a heavy rainfall event occurred during 25-28 June 2005 along the west coast of India. The Indian conventional and nonconventional observations are used in the 3DV experiment. Three numerical experiments are conducted using WRF modeling system, the model is integrated upto 54 hours from the initial time 0000 UTC of 25 June 2005. It is noticed that the meteorological parameters are improved in the resulting high-resolution analyses prepared by NUD and 3DV compared to without data assimilation experiment (i.e., called CNTL experiment). However, after the successful inclusion of observations using the 3DVAR data assimilation technique, the model is able to simulate better structure of the convective organization as well as prominent synoptic features associated with the mid-tropospheric cyclones (MTC) than the NUD experiment and well correlated with the observations. The simulated location and intensity of rainfall is also improved in 3DV simulation as compared with other experiments. Similar results are noticed in the root mean squar errors, correlation coefficients, and Equitable Threat Scores between TRMM and model simulated rainfall for all the three experiments.

\section{Introduction}

Most of the rainfall along the Indian Peninsula during the southwest monsoon (SWM) occurs in association with convective activity over the Arabian Sea (AS) and the Bay of Bengal (BOB) that propagates into the peninsular India. These rainfall activities are usually associated with mesoscale convective systems (MCSs) embedded in large-scale synoptic system. Several investigators have also studied the interaction of the low-level jet with Western Ghats which lead to substantial rainfall during SWM along the west coast of India. The analysis by the authors in [1] shows that the maximum rainfall rate along the west coast of India could be as high as about $20 \mathrm{~cm}$ per day. Previous studies on heavy rainfall $[2,3]$ identified numerous patterns and mechanisms in the synoptic scale and mesoscale that promote heavy rainfall developments and established linkage between heavy rainfall events along with wide variety of synoptic features.

There have been considerable improvements in highresolution mesoscale models over the past few decades. The mesoscale models have shown increased skill in producing not only the correct rainfall intensity and location but also the timing of evolution of the convection over the Indian region [4-6]. The forecast performance of the mesoscale models critically depends on the accuracy of the initial conditions [7]. Typically, large-scale global analyses provide the initial conditions for mesoscale models. These initial conditions have limitations such as coarse resolution and inadequate representation of localized mesoscale processes. Therefore, data assimilation deduces that ingestion of local 
observations is important to develop improved analyses [8]. There are, however, relatively few assimilation studies over the Indian monsoon region and have yielded mixed results. The study in [9] found positive impact of ingesting special observations available from the Arabian Sea Monsoon Experiment (ARMEX-II) on the operational India Meteorological Department (IMD) limited area forecast system. The authors in [10] studied the effect of assimilated satellite and conventional data on the prediction of three monsoon depressions over the Indian region using nudging technique with MM5 and found an overall positive impact on the model performance. Similarly, the authors in [5] carried out a study with MM5 to find out the impact of nudging technique in the modeling system and its performance to simulate the convective episodes leading to heavy rainfall events over the AS off the west coast of India during the ARMEX-2002. The nudging technique has its own limitations such that the small values of the nudging coefficient are chosen to avoid over adjustment.

The three-dimensional variational data assimilation (3DVAR) approach is one of the most promising techniques available to assimilate directly the heterogeneous observations in order to improve the estimate of the models initial state. The authors in $[11,12]$ have attempted to investigate the applications of the 3DVAR assimilation system over the Indian region. The impact of inclusion of various conventional and nonconventional observations in the mesoscale models have been evaluated within these studies for the prediction of heavy rainfall events and depressions over the Indian region. The prime objective of this paper is a performance-based comparison study between the analysis nudging and 3DVAR data assimilation system in simulating heavy rainfall event from 25 to 28 June 2005 along the west coast of India. Section 2, the synoptic situation associated with the heavy rainfall event of 25 to 28 June 2005 is provided. A brief description of the WRF and WRF3DVAR modeling systems is presented in Section 3. The numerical experiments conducted in this study are described in Section 4, and the simulation results are discussed in Section 5. Section 6 presents the conclusions of the study.

\section{Synoptic Conditions during the Heavy Rainfall Event}

The heavy rainfall is due to offshore trough observed at sea level from Saurashtra and Kutch to the Kerala coast which persisted for the whole period. A cyclonic circulation between heights 3.3 and $5.8 \mathrm{~km}$ developed over Gujarat region on 25 June 2005, and the heavy rainfall continually intensified until the 28th. During this intense synoptic event, an unusual 24 hour period of heavy rainfall (more than $200 \mathrm{~mm}$ lasting three days) was recorded over south and central Gujarat and led to a devastating flood situation in several parts of Gujarat. According to media reports, a total of 202 people lost their lives, and approximately 1.76 lakhs people were left homeless.

Kalpana-1 satellite images (Figure 1) show a consistent convective band of clouds over the region. A cyclonic circulation between 3.3 and $5.8 \mathrm{~km}$ developed over Gujarat region on 25th June 2005, and the heavy rainfall continually intensified till 28th June. The IMD subjectively analyzed wind fields (Figure 2) show this cyclonic circulation over the northwest Bay. Scattered to broken intense convection has been observed over the Arabian Sea off the coasts of Gujarat to Kerala. On 26th June 2005, a cyclonic circulation was observed over the northwest Bay of Bengal which extended up to mid-tropospheric levels (Figures 2(c) and 2(d)). Under the influence of this cyclonic circulation over the northwest Bay and surrounding area, a low pressure area formed over the northeast Bay adjacent to Gangetic West Bengal and northern Orissa (along $75^{\circ} \mathrm{E}-80^{\circ} \mathrm{E}$, and $20^{\circ} \mathrm{N}-25^{\circ} \mathrm{N}$ ) (Figures 2(e) and 2(f)). On 28th June 2008, it concentrated into a depression and got spread over Jharkhand and neighbourhood, centred near Jamshedpur, and the system was moving in a westerly direction.

\section{Modeling System}

3.1. Weather Research and Forecasting Model and Data Assimilation Setup. This section explains briefly three aspects such as WRF modeling system, 3DVAR data assimilation, and analysis nudging techniques.

The Weather Research and Forecasting (WRF-ARW version 3.0) modeling system is a next generation of mesoscale model developed by National Center for Atmospheric Research (NCAR) Mesoscale and Microscale Meteorology (MMM) Division Collaboration within a number of research and operational organizations of USA. A detailed description of the WRF model equations, physics, and dynamics is available in $[13,14]$. A logical combination of variety of physical parameterization schemes and data assimilation techniques makes the model capable of simulating meteorological events at different scales.

In variational method, direct minimization of a cost function determines the analysis. The aim of the WRF3DVAR system is to seek an estimate of the analyzed atmospheric state through the iterative solution of a prescribed cost function. Further details about the components and real-time applications of the 3DVAR data assimilation system have been reported in [15].

In the grid nudging, Newtonian relaxation terms are added to the prognostic equations for wind, temperature, and moisture fields. The model linearly interpolates the analyses in time to determine the value towards which the model relaxes its solution. The model values are relaxed towards the analysis using the nudging terms. This process can be described in the model for any variable $\alpha$, the detail description of the analysis nudging and nudging term for a given variable $\alpha$ have been reported in [16]. The details of the analysis nudging linked with WRF-ARW can be found in [17].

\section{Numerical Experiments}

The WRF model with single domain $(30 \mathrm{~km}$ horizontal resolution) is used for simulation of such heavy rainfall event 


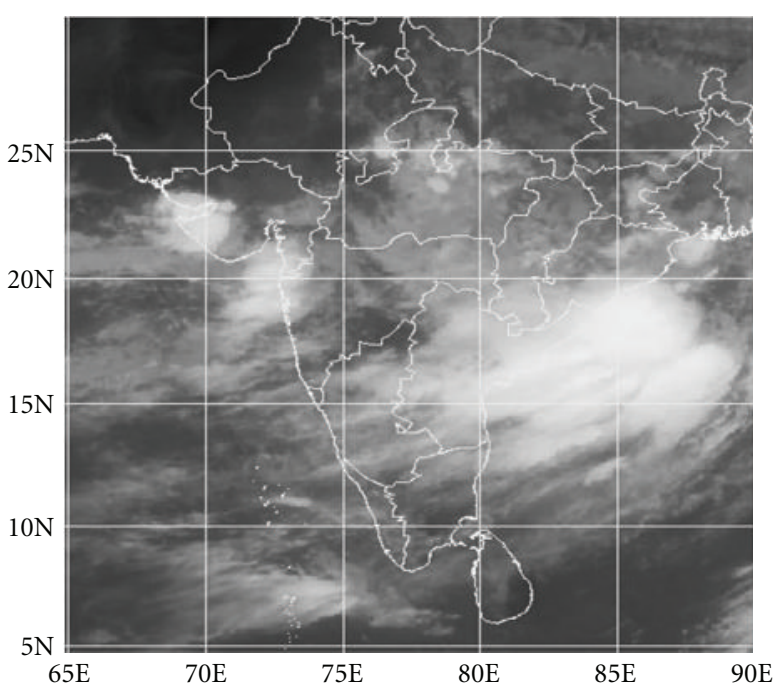

(a) 0000 UTC 25062005

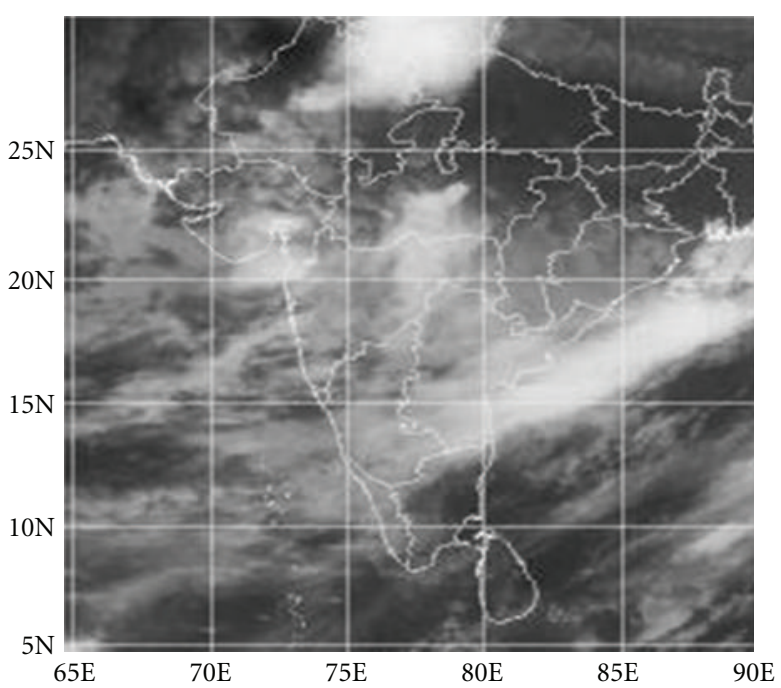

(b) 0000 UTC 26062005

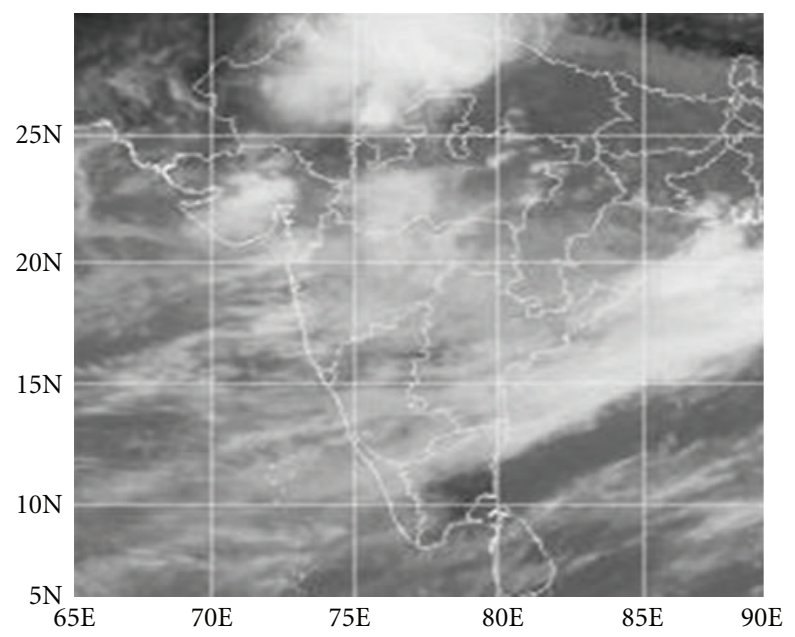

(c) 0000 UTC 27062005

FIgURE 1: (a)-(c): Kalpana-1(IR) satellite pictures valid at 0000 UTC for (a) 25062005, (b) 26062005, and (c) 27062005.

occurred along the west coast of India. For this purpose, three different numerical experiments are carried out. The domain of the model simulations are fixed at $151 \times 151$ grid points in the longitudinal and latitudinal directions along with 32 sigma levels in vertical direction (Figure 3). The first experiment, namely, the control simulation (CNTL) is carried out without data assimilation and the model's initial and boundary conditions are provided by the National Centers for Environmental Prediction (NCEP) final analysis $\left(\mathrm{FNL} ; 1^{\circ} \times 1^{\circ}\right)$. The second experiment, that is, the nudging simulation (NUD), is carried out after the model initial and boundary conditions which are improved with 12 hours analysis nudging before the start of actual forecast. The third experiment, known as "3DV," is carried out after the model's initial condition is modified with the insertion of additional observational data through the 3DVAR data assimilation system. The conventional and nonconventional observations received through Global Telecommunication System (GTS) are used in the assimilation experiments. Modules have been developed for reading the decoded observed data from GTS and for making suitable format (LITLE_R) in the frame work of 3DVAR observation preprocessor. Figure 4 shows the distribution of the upper air and surface network which is used in the assimilation process. The details of the data sets used in the assimilation experiment are given in Table 1. In all the three experiments, the model is integrated for $54 \mathrm{hrs}$ from the initial time 0000 UTC of 25 June 2005. The detail model configurations with physics and dynamics used in the study are given in Table 2.

\section{Results and Discussion}

The WRF modeling system is integrated from 0000 UTC of 25 June to 0600 UTC of 27 June 2005 for all the three experiments. The results are presented in the following subsections. A comparative study is carried out between the low-resolution global analyses (FNL) and the highresolution analyses prepared by NUD and 3DV experiments, 


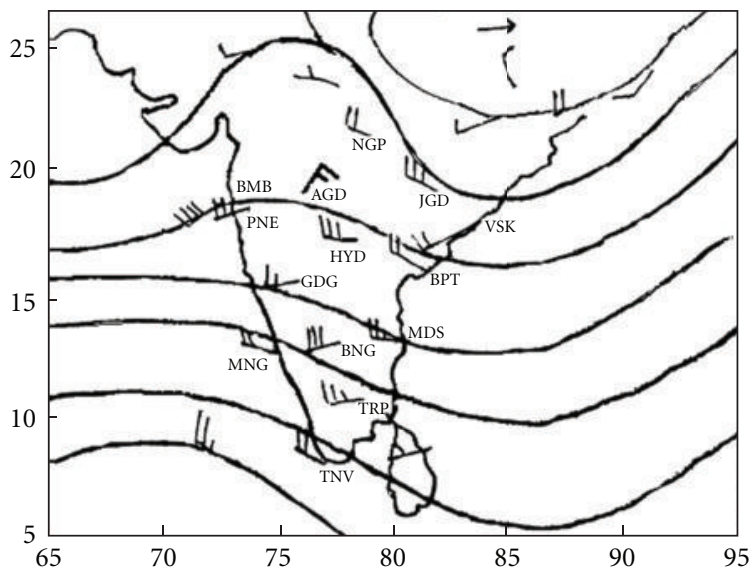

(a) $850 \mathrm{hPa}$ (00UTC 25062005)

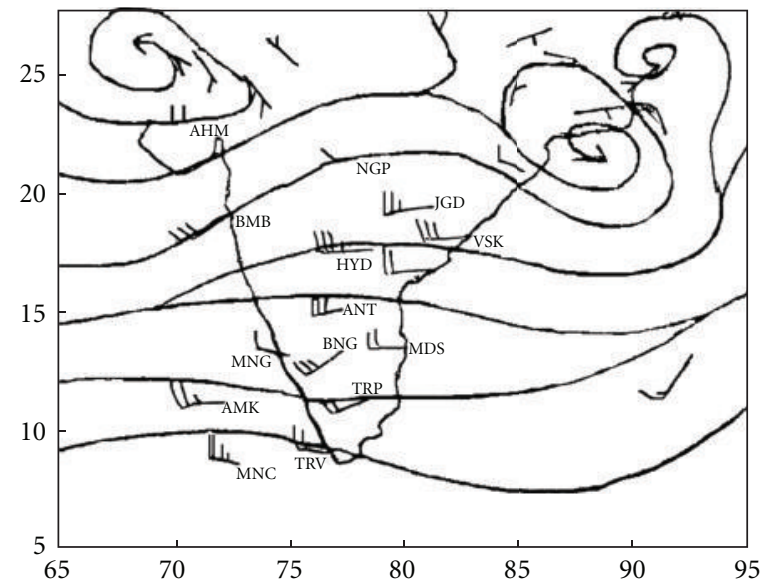

(c) $850 \mathrm{hPa}$ (00UTC 26062005)

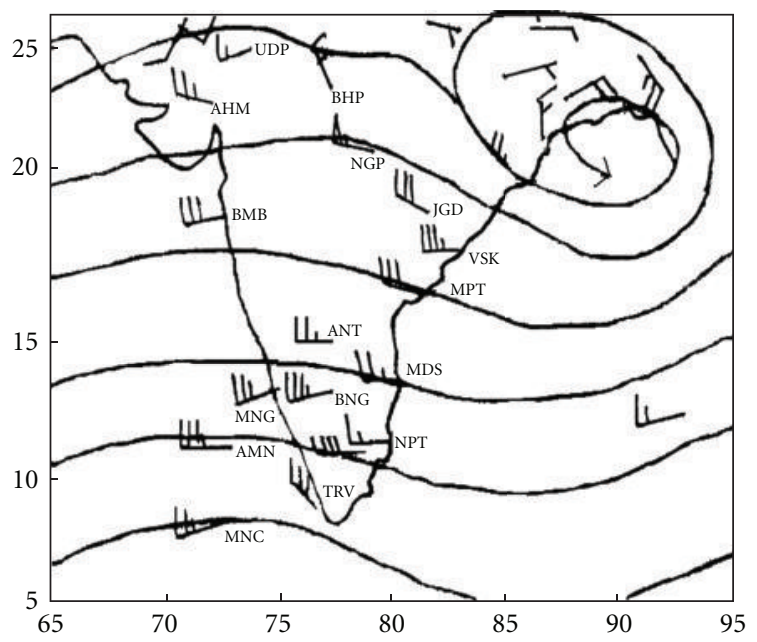

(e) $850 \mathrm{hPa}$ (00UTC 27062005)

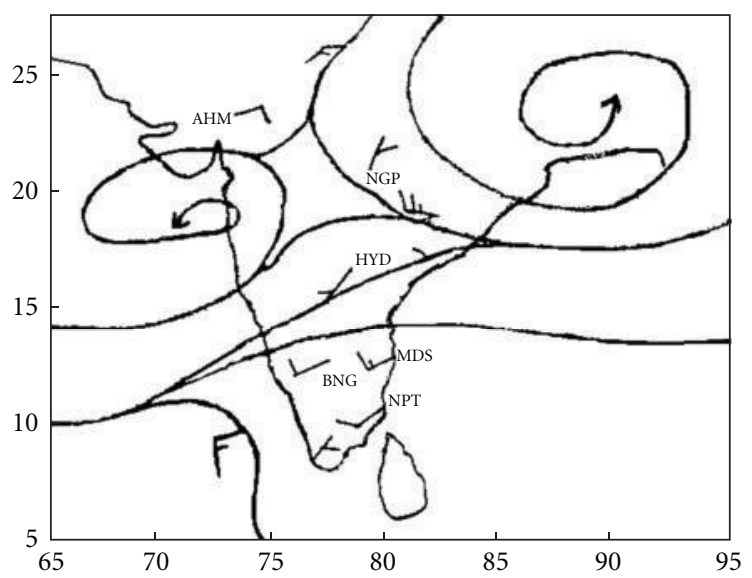

(b) $500 \mathrm{hPa}$ (00UTC 25062005)



(d) $500 \mathrm{hPa}$ (00UTC 26062005)

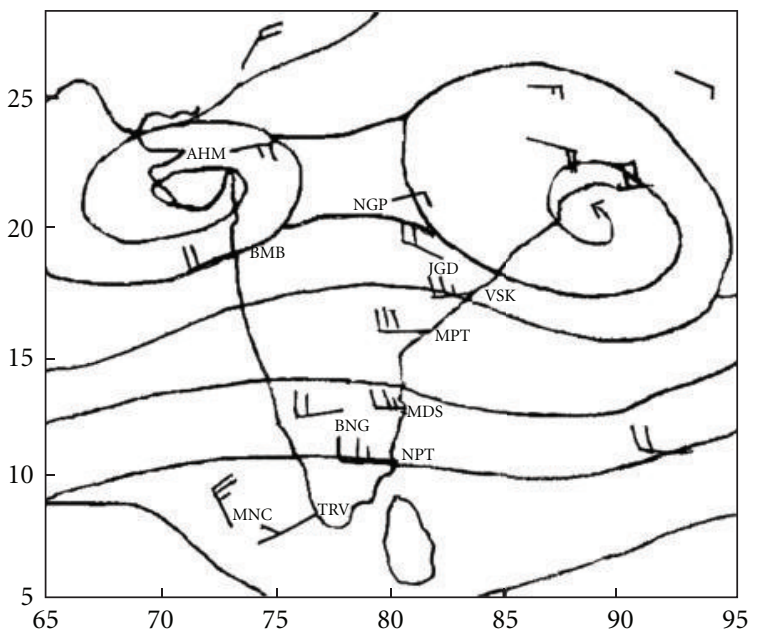

(f) $500 \mathrm{hPa}$ (00UTC 27062005)

FIgURE 2: (a)-(f): Stream line analysis with observed wind valid at 0000 UTC 25062005 for (a) $850 \mathrm{hPa}$ and (b) $500 \mathrm{hPa}$ (c) and (d) are the same as (a) and (b), respectively, but valid at 0000 UTC 26062005. (e) and (f) are the same as (a) and (b), respectively, but valid at 0000 UTC 27062005. 
TABLE 1: Description of observation data sets used in the assimilation experiments.

\begin{tabular}{lll}
\hline Serial number & Data & Description \\
\hline 1 & SYNOP & Surface observations from land stations \\
2 & BUOY & Drifting and moored buoy observations \\
3 & SHIP & Ship observations from sea \\
4 & TEMP & Upper-air profiles of temperature, humidity, and wind from radiosonde \\
5 & PILOT & Wind profiles from optical theodolite \\
6 & AIREP/AMDAR & Upper-level wind and temperature reported by aircrafts \\
7 & SATOB & Satellite-observed cloud motion vectors from Kalpana-1, METEOSAT-6, GMS, and GOES \\
8 & SATEM & Satellite-observed wind and total precipitable water from NOAA satellites \\
\hline
\end{tabular}

TABLE 2: WRF Model configuration used in the present study.

\begin{tabular}{ll}
\hline Dynamics & Nonhydrostatic \\
Main prognostic variables & $u, v, w, p^{\prime}, \theta^{\prime}, \Phi^{\prime}$ \\
Number of domain & Single domain \\
Central point of the domain & Central Lat/Lon.: $17.0^{\circ} \mathrm{N} / 78.0^{\circ} \mathrm{E}$ \\
Horizontal grid distance & $30 \mathrm{~km}$ \\
Integration time step & 90 second \\
Number of grid points & $X$ - and $Y$-direction $151 \times 151$ points \\
Map projection & Mercator \\
Horizontal grid distribution & Arakawa C-grid \\
Vertical coordinate & Terrain-following hydrostatic-pressure coordinate \\
Time integration & 3rd-order Runge-Kutta \\
Spatial differencing scheme & 6th-order centered differencing \\
Initial conditions & 3-dimensional real-data (FNL: $1^{\circ} \times 1^{\circ}$ ) \\
Lateral boundary condition & Specified options for real-data \\
Microphysics & Lin \\
Radiation scheme & Dudhia's short wave radiation/RRTM long wave \\
Surface layer parameterization & Thermal diffusion scheme \\
Cumulus parameterization schemes & Betts-Miller-Janjic \\
PBL parameterization & YSU scheme \\
\hline
\end{tabular}

provided in Section 5.1. The high-resolution analyses are provided as the initial condition for the model integration. The impact of WRF model simulations based on improved model initial conditions are examined in Section 5.2, where the predicted meteorological fields are compared with the available observations.

5.1. Improvement in Model Initial Time. A comparative discussion of FNL and modified analyses is presented in this section. A specific investigation has also been carried out in this section to analyze the meteorological setup. The meteorological fields of low-resolution FNL analysis are interpolated to the model grid resolution $(30 \mathrm{~km}$ horizontal resolution) through bilinear interpolation, and comparisons are made among the resulting high-resolution analyses prepared by NUD and 3DV experiments and the interpolated FNL analysis.

5.1.1. Winds. The wind fields from three analyses (FNL, NUD and 3DV) at $850 \mathrm{hPa}$ and $500 \mathrm{hPa}$ levels valid at 0000 UTC 25 June 2005 are shown in Figure 5 and it is seen that

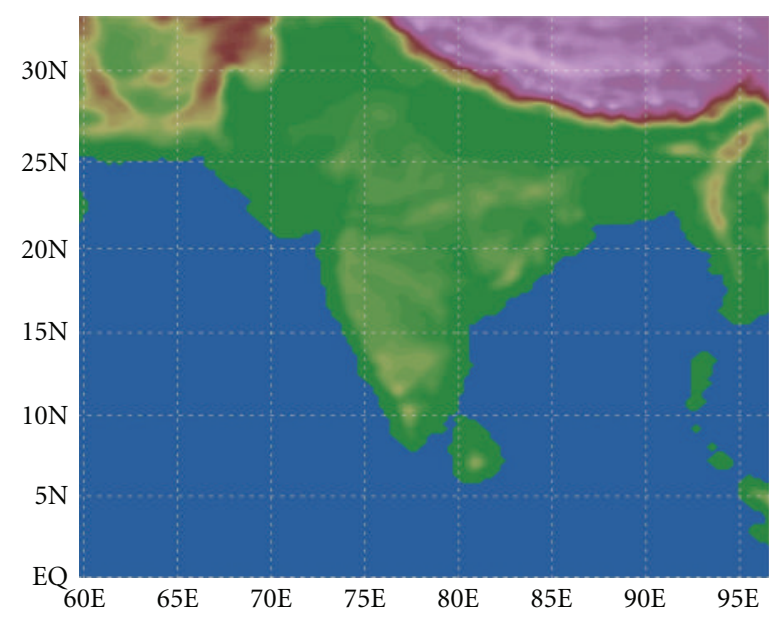

FIgURE 3: Domain chosen for the present study.

the $850 \mathrm{hPa}$ winds show strong westerlies over the AS in all the three analyses. A well-defined trough is noticed in all the 


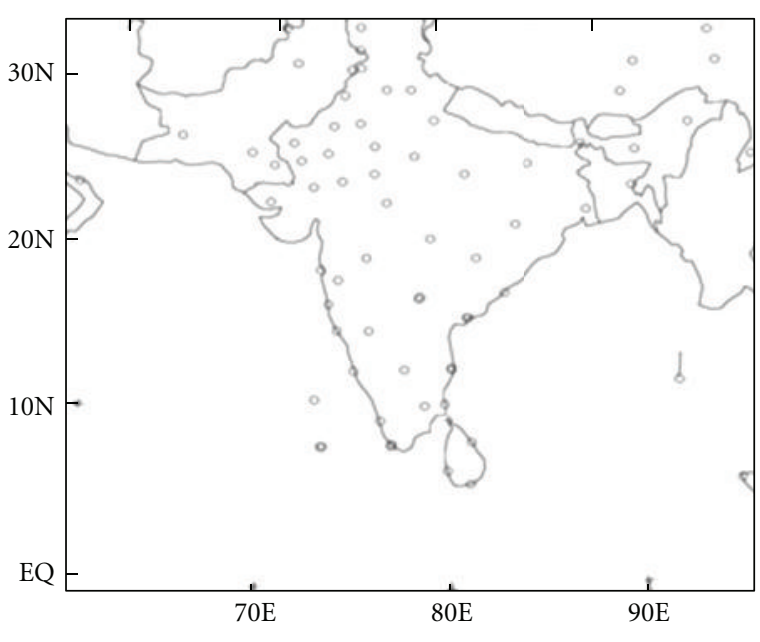

- 68 SOUND 2005-06-25_00

(a)

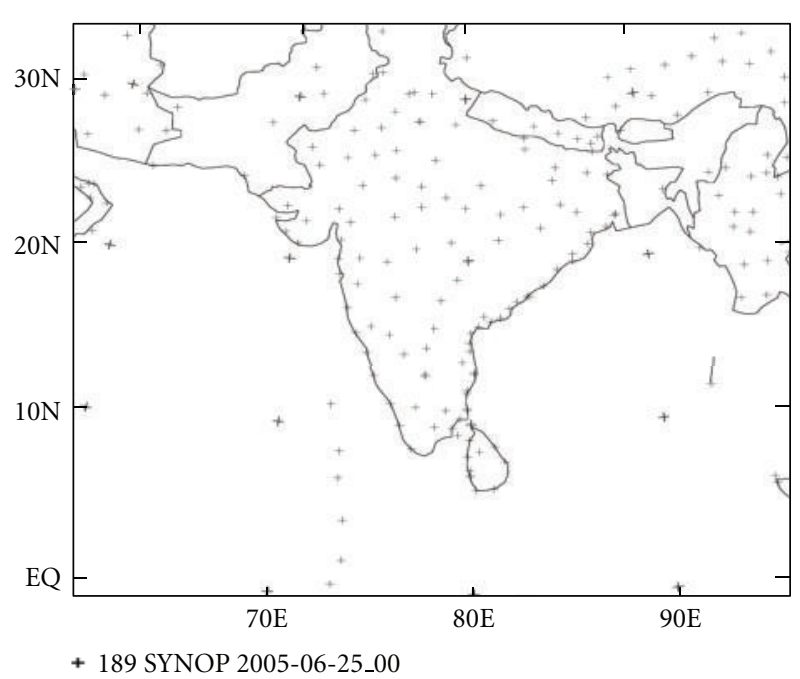

(b)

FIgURE 4: (a)-(b): Distribution of (a) upper air and (b) surface network data used in data assimilation procedure.

three analyses over Gujarat region. The 3DV (Figure 5(c)) shows a strong wind flow pattern $\left(16-20 \mathrm{~m} \mathrm{~s}^{-1}\right)$ over the northeast and central part of the AS, Maharashtra region $\left(\sim 20^{\circ} \mathrm{N}, 75^{\circ} \mathrm{E}\right)$ and also elongated over the western part of Madhya Pradesh $\left(\sim 22^{\circ} \mathrm{N}, 82^{\circ} \mathrm{E}\right)$, but the FNL (Figure 5(a)) and NUD (Figure 5(b)) analyses have failed to reproduce the wind pattern. However, the NUD analysis shows a small patch of strong wind flow pattern over the central part of the AS and Maharashtra region compared to the FNL analysis. The magnitude of winds over coastal Maharashtra is $16-20 \mathrm{~m} \mathrm{~s}^{-1}$ in $3 \mathrm{DV}$ (Figure $5(\mathrm{c})$ ), which is in good agreement with the radiosonde observations over the region (Figure 2(a)). A similar distribution of wind flow pattern (magnitude 10-12 $\mathrm{m} \mathrm{s}^{-1}$ ) is also found over the Konkan-Goa region $\left(\sim 15^{\circ} \mathrm{N}, 76^{\circ} \mathrm{E}\right)$ in all the three analyses. At the same time, however, a strong swath of wind $\left(16-18 \mathrm{~m} \mathrm{~s}^{-1}\right)$ is found in $3 \mathrm{DV}$ over the central Karnataka region $\left(\sim 12^{\circ} \mathrm{N}, 77^{\circ} \mathrm{E}\right)$ which is close to the IMD radiosonde observations over the region, but absent in FNL and NUD analyses.

Similarly, in 3DV analysis at $500 \mathrm{hPa}$ (Figure 5(f)), it is deduced that wind speed of magnitude $8-12 \mathrm{~m} \mathrm{~s}^{-1}$ is located over AS along the west coast of India and the interior part of the Maharashtra and Karnataka regions, which is missing from other two analyses (FNL and NUD). But a small strong patch of wind (10-12 $\left.\mathrm{m} \mathrm{s}^{-1}\right)$ over the north part of the AS is found in the NUD analysis (Figure 5(e)), which is not found in the FNL analysis (Figure 5(d)). Though a cyclonic circulation is found in the FNL (Figure 5(d)) and NUD (Figure 5(e)) analyses over the Saurashtra and Kutch region $\left(\sim 22^{\circ} \mathrm{N}, 73^{\circ} \mathrm{E}\right)$, its position disagrees with the subjective IMD analysis as shown in Figure 2(b). The position of the MTC is observed over the southern parts of Gujarat and the Mumbai region $\left(\sim 20^{\circ} \mathrm{N}, 73^{\circ} \mathrm{E}\right)$ in the IMD observation. The 3DV is restricted because of missing upper-air data for 0000 UTC of 25 June 2005 over the region. The improvement found in the 3DV can be due to the assimilation of the cloud motion vectors from satellites along with additional surface data over the region.

5.1.2. Vertical Cross-Sections. Figure 6 shows the vertical cross-section (meridional and zonal) of the wind components from all the three analyses along $72.8^{\circ} \mathrm{E}$ and $21.1^{\circ} \mathrm{N}$ valid at 0000 UTC of 25 June 2005 . The figures show that the zonal circulation feature is generally symmetrical with height in all the analyses and weaker in the FNL and NUD analyses as compared with 3DV analysis. In the resultant 3DV analysis (Figure 6(c)), westerly flows at the southern side of the center of the cyclonic circulation are stronger by a magnitude of $4 \mathrm{~m} \mathrm{~s}^{-1}$ and $2 \mathrm{~m} \mathrm{~s}^{-1}$ as compared to the FNL and NUD analyses, respectively. In the modified analyses (Figures 6(b) and $6(\mathrm{c})$ ), the strongest westerly flows are found near the surface level (around $900 \mathrm{hPa}$ ). But the strongest easterly flows are seen upper the pressure level (above $400 \mathrm{hPa}$ ) in all the analyses. The zonal cross-section of the $v$-component illustrates that the flow pattern in the analyses are generally more symmetrical around the axis. The maximum southerly flow in the eastern sector of the cyclonic circulation due to NUD and 3DV (Figures 6(e) and 6(f)) is located near the surface around $900 \mathrm{hPa}$. The strong northerly flow $\left(10 \mathrm{~m} \mathrm{~s}^{-1}\right)$ is found in the $3 \mathrm{DV}$ analysis around $600 \mathrm{hPa}$; however, the representation is missing in FNL (Figure 6(d)) and NUD (Figure 6(e)) analyses.

The vertical cross-section of relative vorticity field along the longitude $72.8^{\circ} \mathrm{E}$ and latitude $21.1^{\circ} \mathrm{N}$ valid at $0000 \mathrm{UTC}$ of 25 June 2005 is presented in Figures 7(a)-7(f). The figures illustrate the structural difference in the relative vorticity field between the analyses. The dashed lines represent the negative vorticity and thick lines represent positive vorticity, which causes the system to intensify. The high-resolution analyses (Figures $7(\mathrm{~b})$ and $7(\mathrm{c})$ ) show a positive vorticity in the lower atmosphere around $850 \mathrm{hPa}$ and a secondary 
$850 \mathrm{hPa}$

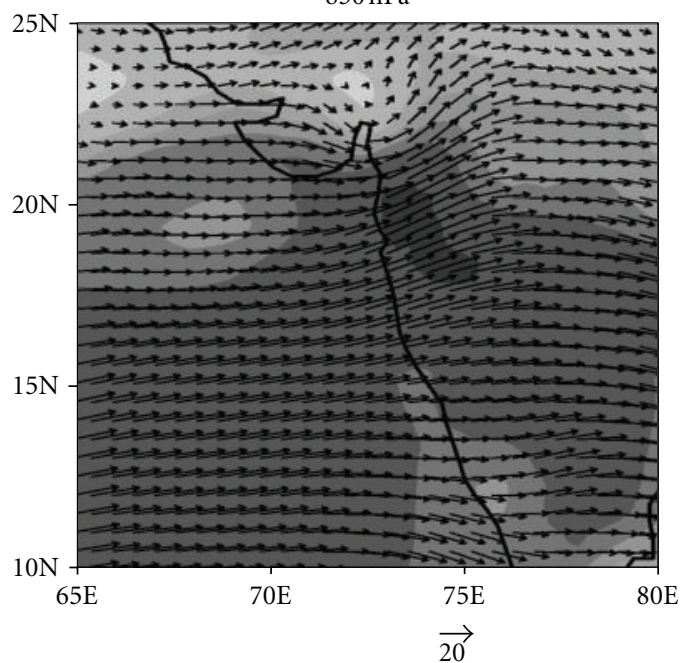

(a)

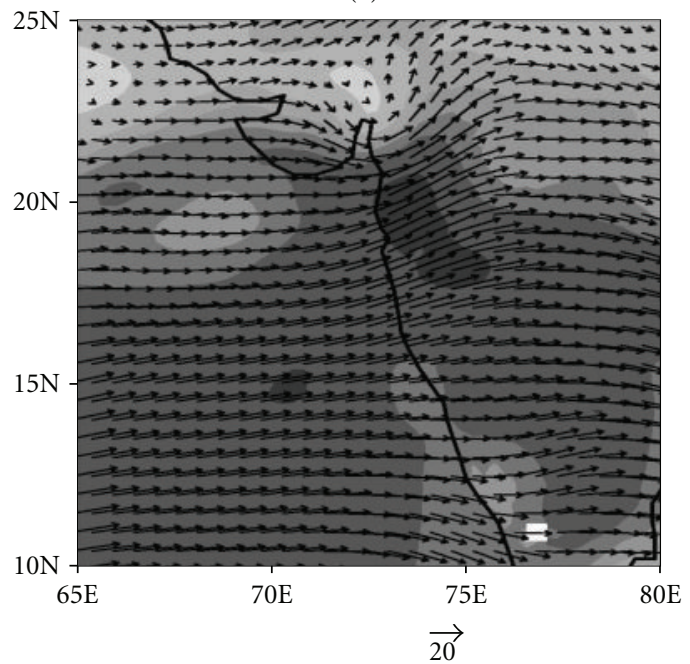

(b)

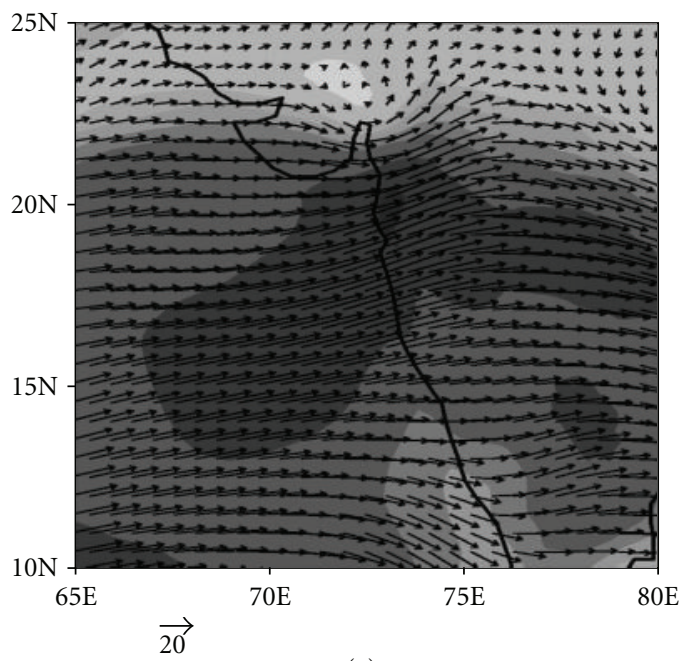

$500 \mathrm{hPa}$

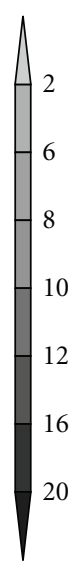

$10 \mathrm{~N}$

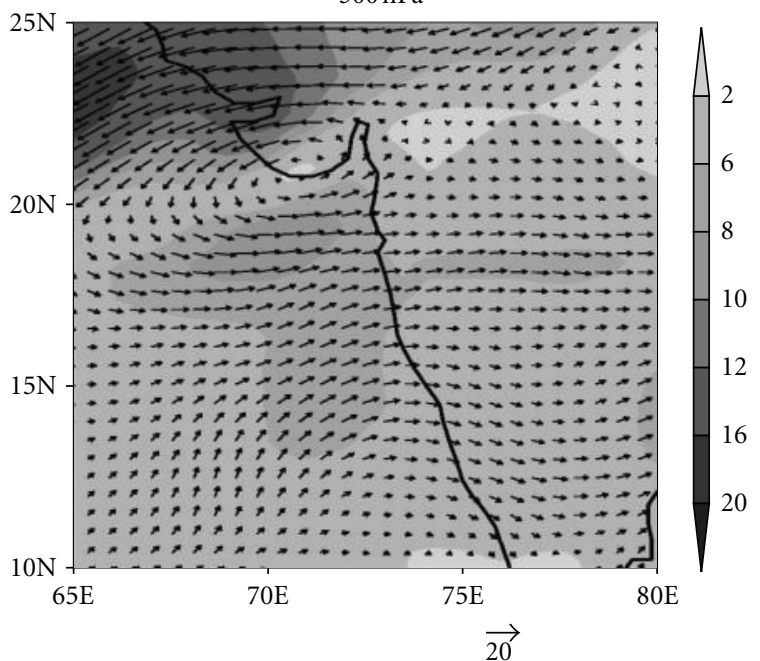

(d)

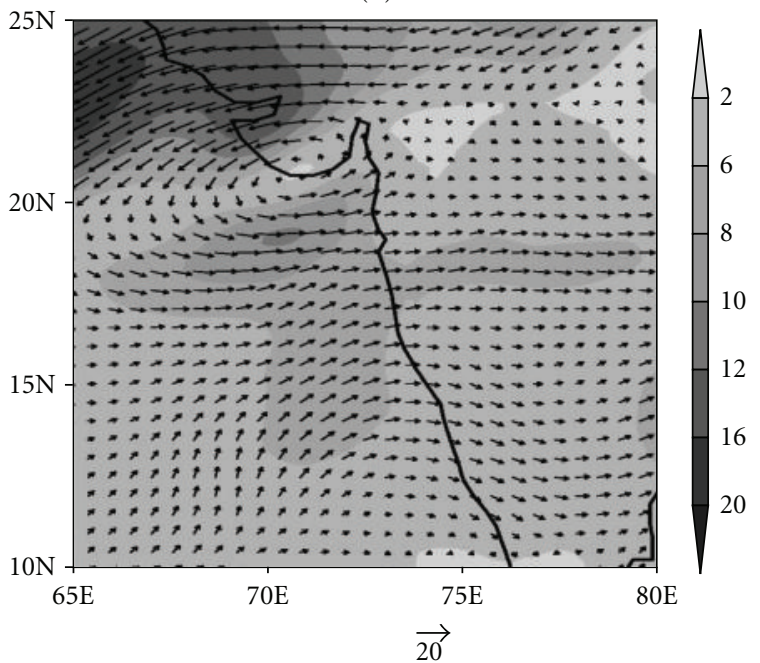

(e)

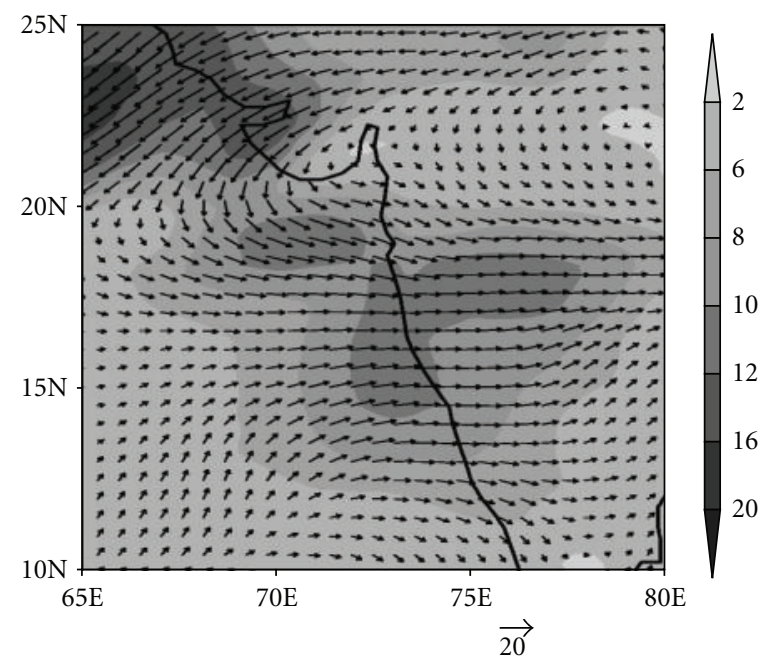

(f)

Figure 5: (a)-(f): Wind vector and speed (in shaded, $\mathrm{m} \mathrm{s}^{-1}$ ) at 850 hpa for (a) FNL ANA; (b) NUD and (c) 3DV valid at 0000 UTC on 25 June 2005. (d)-(f) are the same as (a)-(c), respectively, but at pressure level $500 \mathrm{hPa}$. 


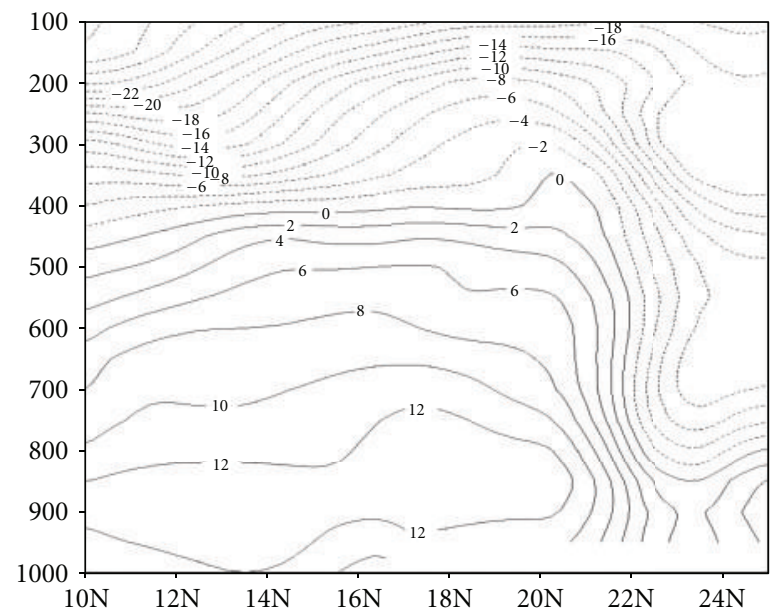

(a)

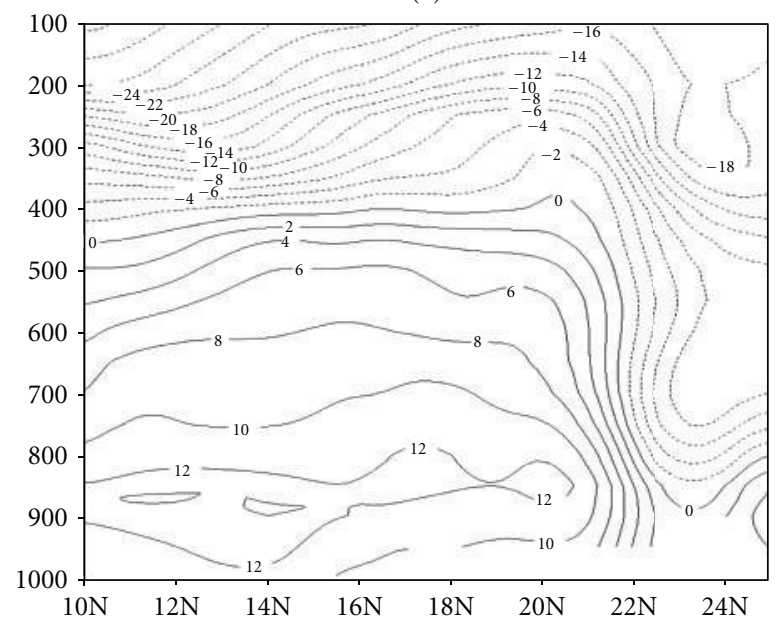

(b)

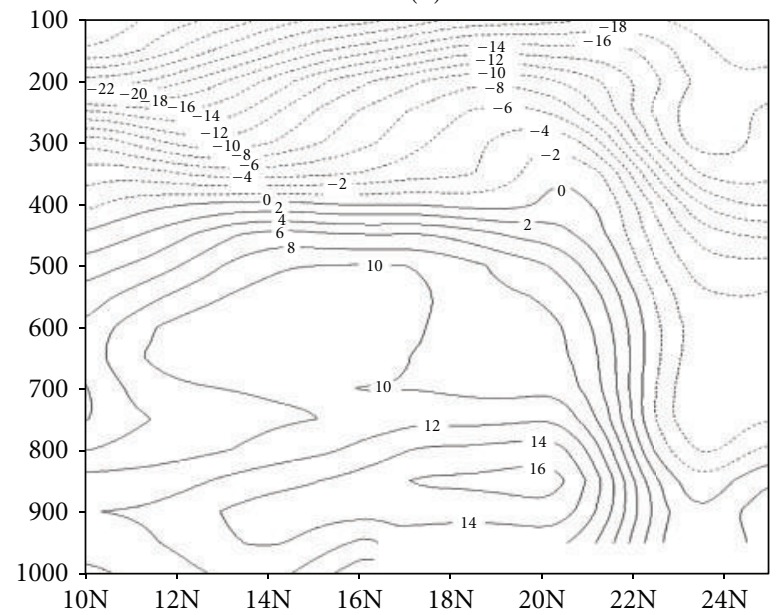

(c)

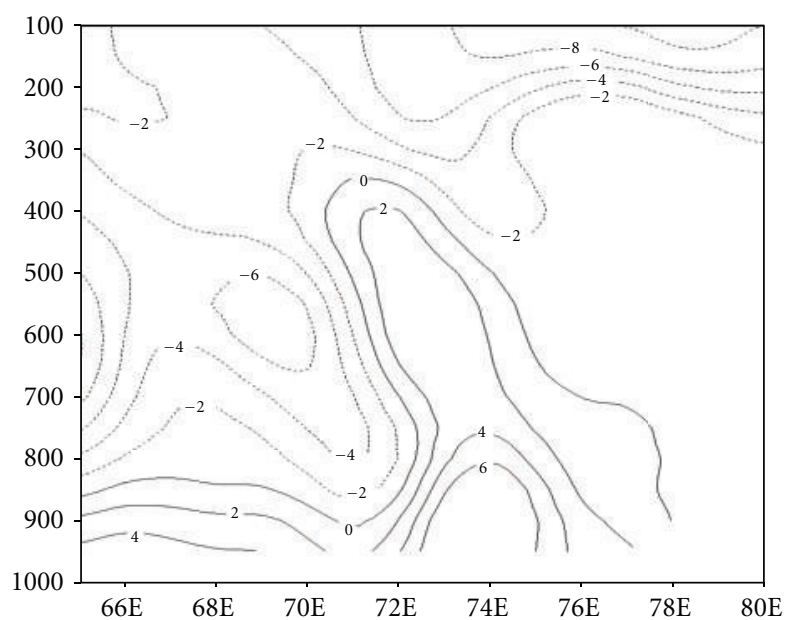

(d)

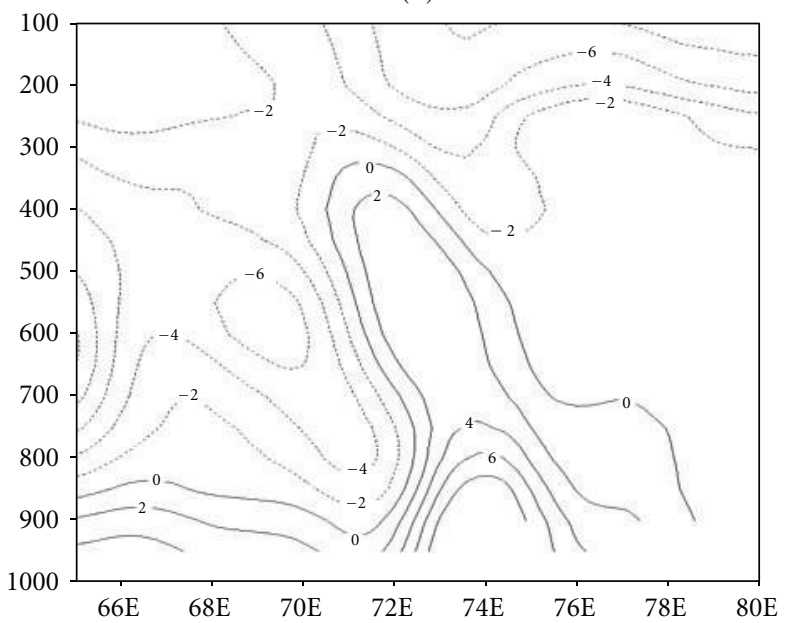

(e)

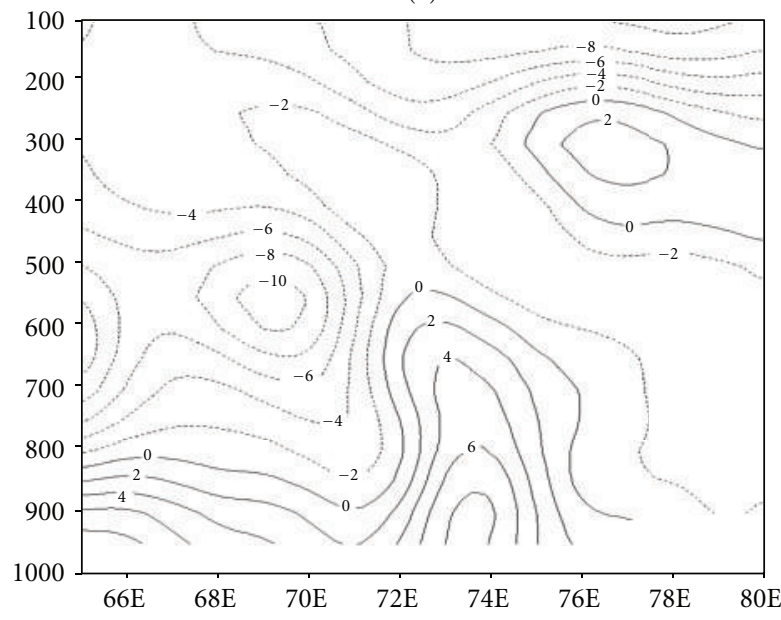

(f)

FIgURE 6: (a)-(f): Vertical cross-sections of wind components with contour interval $2 \mathrm{~m} \mathrm{~s}^{-1}$ valid at 0000 UTC on 25 June 2005 ; meridional cross-section of zonal wind ( $u$-component) along $72.8^{\circ} \mathrm{E}$ for (a) FNL ANA; (b) NUD and (c) 3DV. (d) $-(\mathrm{f})$ are the same as (a)-(c), respectively, but for zonal cross-section of meridional wind ( $v$-component) along $21.1^{\circ} \mathrm{N}$. 


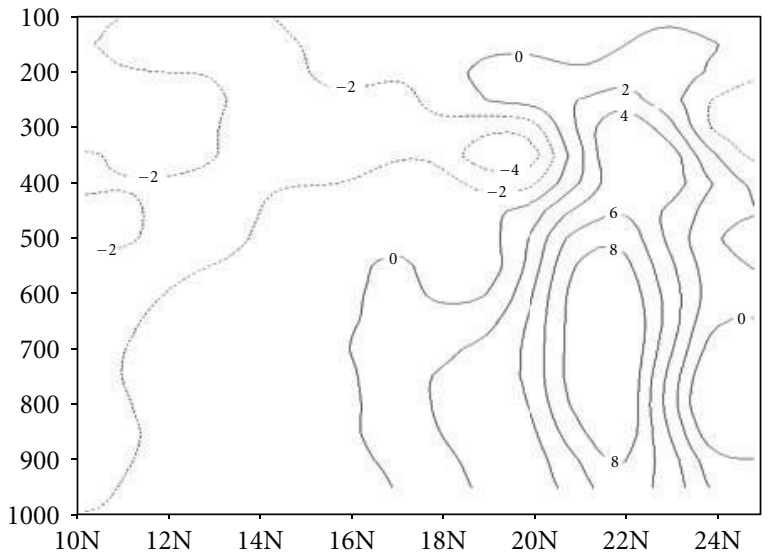

(a)

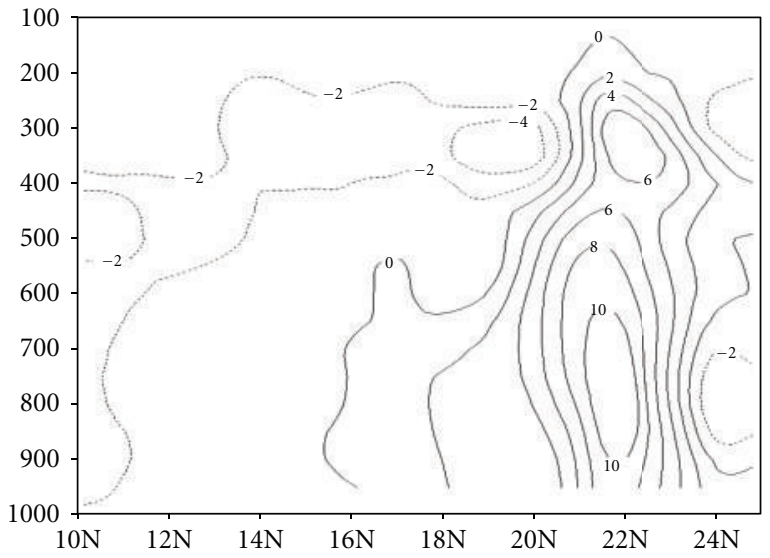

(b)

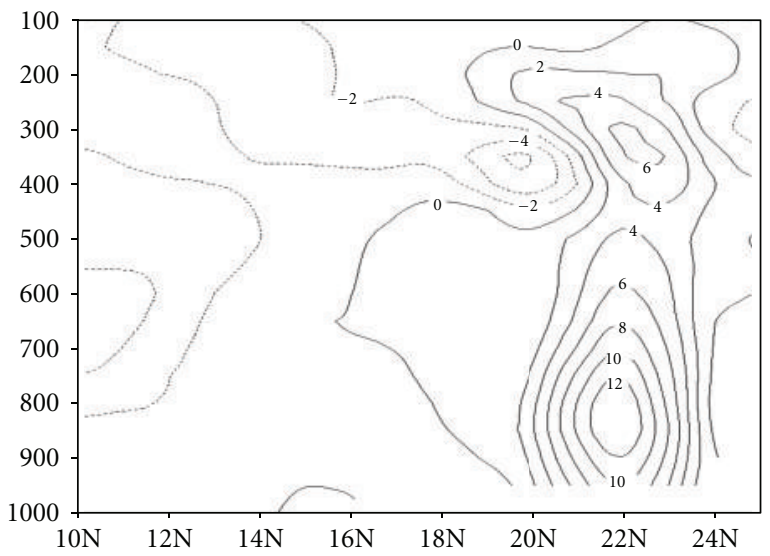

(c)

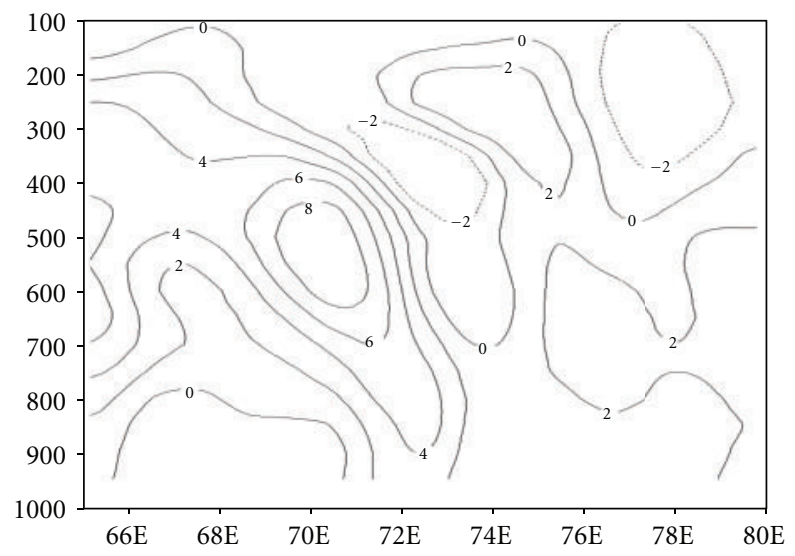

(d)

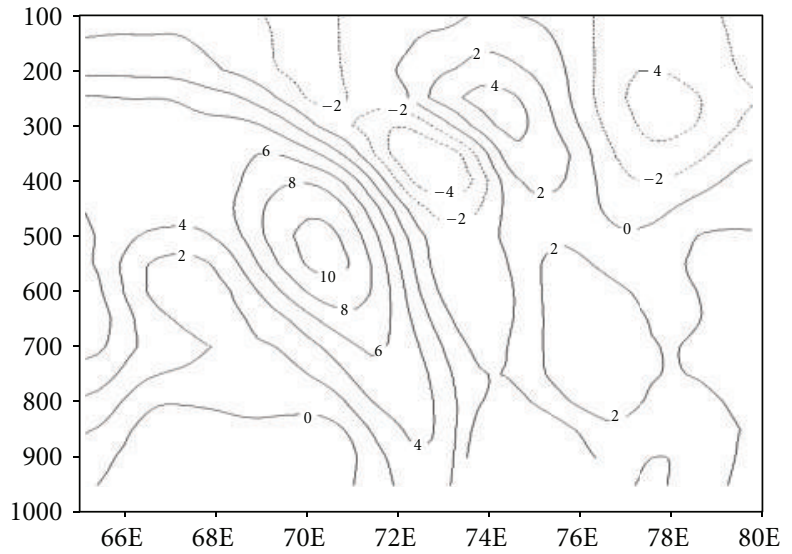

(e)

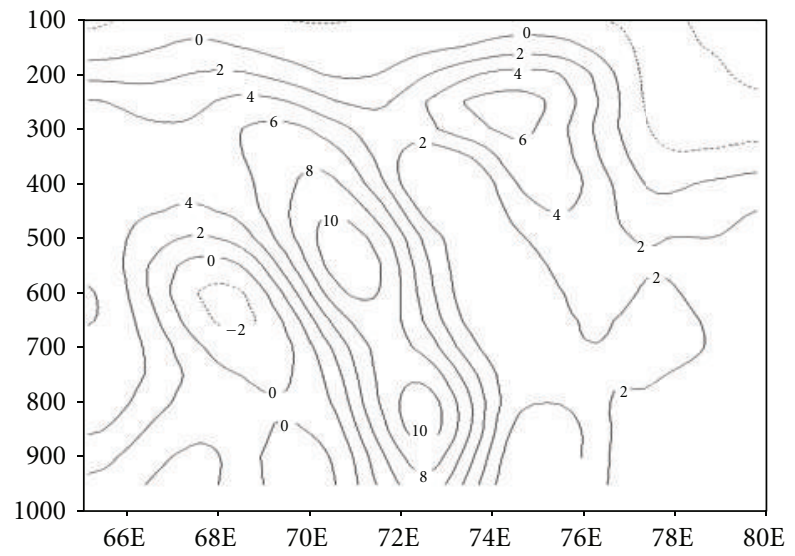

(f)

FIgURE 7: (a)-(f): Meridional cross-section of vorticity (interval $2 \times 10^{-5} \mathrm{~s}^{-1}$ ) along $72.8^{\circ} \mathrm{E}$ for (a) FNL ANA, (b) NUD and (c) 3DV valid at 0000 UTC on 25 June 2005. (d)-(f) are the same as (a)-(c), respectively, but for zonal cross-section of vorticity along $21.1^{\circ} \mathrm{N}$.

maximum at $350 \mathrm{hPa}$. Contrary to this, the FNL analysis (Figure 7(a)) shows one maximum near $850 \mathrm{hPa}$ and the values are in lower side as compared to the other two analyses (NUD and 3DV). In the 3DV analysis, (Figure 7(c)), the strong positive vorticity $\left(12 \times 10^{-5} \mathrm{~s}^{-1}\right)$ near the surface and negative vorticity $\left(-6 \times 10^{-5} \mathrm{~s}^{-1}\right)$ around $350 \mathrm{hPa}$ are noticed. However, the exact values are not observed in the NUD analysis (Figure 7(b)).

The vertical cross-section of the relative vorticity along the latitude $21.1^{\circ} \mathrm{N}$ from all the three analyses is represented in Figures $7(\mathrm{~d})-7(\mathrm{f})$. The cyclonic vorticity in the high-resolution analyses (Figures $7(\mathrm{e})$ and $7(\mathrm{f})$ ) are more 
intensified as compared to FNL analysis (Figure 7(d)). In the 3DV analysis, (Figure 7(f)), shows a positive vorticity $\left(10 \times 10^{-5} \mathrm{~s}^{-1}\right)$ near the surface pressure level around $850 \mathrm{hPa}$ and $6 \times 10^{-5} \mathrm{~s}^{-1}$ at $300 \mathrm{hPa}$ which is missing in the NUD analysis (Figure 7(e)). The positive improvements have been found at the model initial time after assimilation of Indian conventional and nonconventional observations through 3DVAR data assimilation.

5.2. Impact on the WRF Model Simulation. In this section, the impact of WRF model simulations with the high-resolution analyses prepared by 3DVAR data assimilation and analysis nudging techniques based as model initial conditions is examined.

5.2.1. Wind. Figures 8 and 9 show the model simulated wind fields valid for 0000 UTC of 26 (day 1) and 27 (day 2) June 2005 at two pressure levels $850 \mathrm{hPa}$, and $500 \mathrm{hPa}$, respectively. The wind pattern shows a well-defined and more intense cyclonic circulation in the 3DV simulation compared with other two simulations. The position of the MTC in 3DV simulation closely resembles the zones of intense convective cloud over the region from satellite picture shown in Figure 1(b). For day 1 simulation at $850 \mathrm{hPa}$, it is observed that the NUD simulation (Figure 8(b)) shows strong wind $\left(20-25 \mathrm{~m} \mathrm{~s}^{-1}\right)$ over a large area of interior Maharashtra compared to the CNTL simulation (Figure 8(a)). However, the wind patterns at $850 \mathrm{hPa}$ over AS and west coast of the Mumbai are improved due to 3DV simulation (Figure 8(c)) compared to CNTL and NUD simulations. The magnitude of simulated wind by 3DV experiment along the Mumbai coast is more accurate with the IMD radiosonde observation (Figure 2(c)) over the station. The day 1 model simulated wind field at $500 \mathrm{hPa}$ pressure level from the CNTL, NUD, and $3 \mathrm{DV}$ simulations is illustrated in Figures $8(\mathrm{~d})-8(\mathrm{f})$, respectively. A close cyclonic circulation is found in the $3 \mathrm{DV}$ simulation (Figure $8(\mathrm{f})$ ) over the southern sector of the state of Gujarat that is poorly simulated in both CNTL and NUD simulations. The position of the cyclonic circulation in the $3 \mathrm{DV}$ simulation is considerably close to the IMD observation (Figure 2(d)). The 3DV simulation shows the $12-16 \mathrm{~m} \mathrm{~s}^{-1}$ magnitude wind elongated over a large area west coast Mumbai. Correspondingly, a stronger wind (magnitude 10$12 \mathrm{~m} \mathrm{~s}^{-1}$ ) is observed along the west coast of India, extending from Maharashtra coast to Goa coast and also the interior part of Karnataka region in 3DV simulation (Figure 8(f)) which is absent in CNTL (Figure $8(\mathrm{~d})$ ) simulation, and a small patch of wind with the same magnitude is found off the west coast of Goa in NUD simulation (Figure 8(e)). In particular, the magnitude of wind over Bangalore sounding station $\left(12.5^{\circ} \mathrm{N}, 77.3^{\circ} \mathrm{E}\right)$ in the $3 \mathrm{DV}$ simulation is around $12 \mathrm{~m} \mathrm{~s}^{-1}$ which is close to the IMD observation over the station. Figure 8(f) indicates that the center of the MTC at $500 \mathrm{hPa}$ is located over the AS to the southeast of the $850 \mathrm{hPa}$ position. Therefore, the vertical axis of the MTC in the 3DV simulations tilts southeastward with height. This is a typical characteristic of the cyclonic structure over India as discussed in [18].
For day 2 simulation as shown in Figure 9, the position of the MTC is again well simulated in the $3 \mathrm{DV}$ simulations as compared to CNTL and NUD simulations. At $850 \mathrm{hPa}$, an elongated wind $\left(20-25 \mathrm{~m} \mathrm{~s}^{-1}\right)$ over a large area of AS and also continental landmass is observed in NUD simulation (Figure 9(b)) when compared with other two model simulations. However, the strong patch of wind over northeastern sector of AS is simulated by 3DV experiment (more than $25 \mathrm{~m} \mathrm{~s}^{-1}$ ). The Figures 9(d)-9(f) illustrate the day 2 model simulated wind field at $500 \mathrm{hPa}$ pressure level from CNTL, NUD, and 3DV experiments, respectively. It is worth to mention that the 3DV simulation (Figure 9(f)) has well established the position of the MTC when compared with other model simulations, which closely resembles with the IMD observation (Figure 2(d)). Although, the position of the MTC is well captured in the NUD simulation (Figure 9(e)), but it is seen that the position is little shifted away from the observed position and this feature is poorly simulated in the CNTL simulation (Figure 9(d)).

Figures 10(a)-10(f) show the vertical cross-section of zonal component of wind ( $u$-component) along the longitude $72.0^{\circ} \mathrm{E}$ and $70.5^{\circ} \mathrm{E}$ for day 1 and day 2, respectively. In $3 \mathrm{DV}$ simulation, the maximum westerly flow near the surface on the south side of the center of the MTC is stronger by a magnitude of $3 \mathrm{~m} \mathrm{~s}^{-1}$ during day 1 and day 2 . Such high magnitude of wind is not observed in the CNTL and NUD simulations. It is also noted that the westerly flow near the surface (around $800 \mathrm{hPa}$ ) is improved due to NUD simulations (Figures 10(b) and 10(e)) compared with the CNTL (Figures 10(a) and 10(d)). In day 2, the easterly flows at the northern side of the center of the MTC are stronger by a magnitude of $3 \mathrm{~m} \mathrm{~s}^{-1}$ in the 3DV (Figure 10(f)) as compared to the NUD simulation (Figure 10(e)). Similarly, the zonal cross-section of the $v$-component (figure not provided) in the $3 \mathrm{DV}$ simulation is found at its maximum in the lower and middle of the atmosphere compared to the CNTL and NUD simulations during day 1 and day 2. In day 1 , the maximum southerly flow $\left(15 \mathrm{~m} \mathrm{~s}^{-1}\right)$ near the lower troposphere $(800 \mathrm{hPa})$ in the eastern sector as well as the maximum northerly flow $\left(12 \mathrm{~m} \mathrm{~s}^{-1}\right)$ around $600 \mathrm{hPa}$ in the western sector of the cyclonic circulation is found in the $3 \mathrm{DV}$ as compared with the CNTL and NUD simulations. Similarly for day 2, the maximum northerly and southerly flow (15$18 \mathrm{~m} \mathrm{~s}^{-1}$ ) is found in the 3DV simulation at near the lower troposphere and extended up to mid-troposphere.

5.2.2. Precipitation. The 24 hours accumulated precipitation for day 1 and day 2 as obtained from CNTL, NUD, and 3DV simulations and the observed rainfall from the Tropical Rainfall Measuring Mission (TRMM-3B42) satellite are illustrated in Figures 11(a)-11(h). Comparison of the 24 hours accumulated model rainfall and the surface stations valid at 0300 UTC of 26 and 27 June 2005 are given in Tables 3 and 4. Heavy rainfall is concentrated along the MTC in northern Maharashtra and Gujarat coast. For day 1 and day 2 , the model simulates a well-established closed circulation system in the 3DV experiment (Figures 11(d) and 11(h)). The spatial distribution pattern and amount of rainfall are 


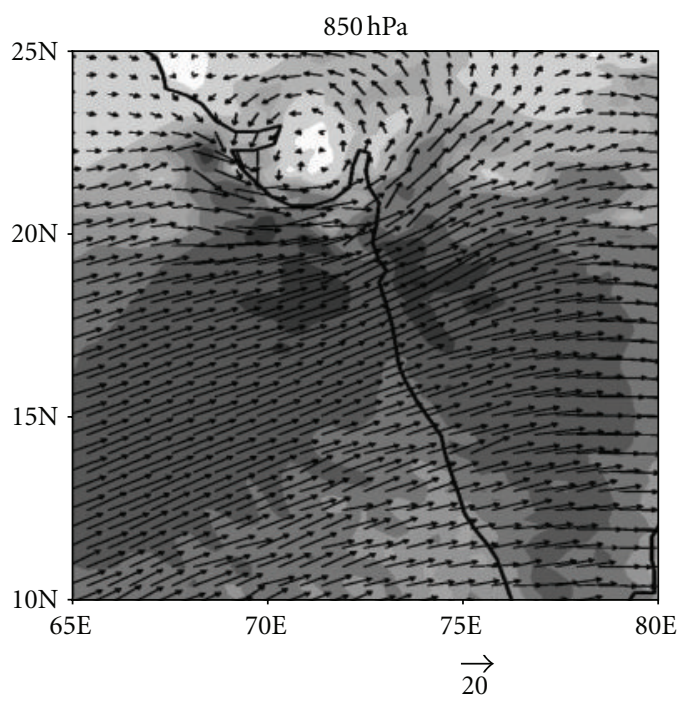

(a)

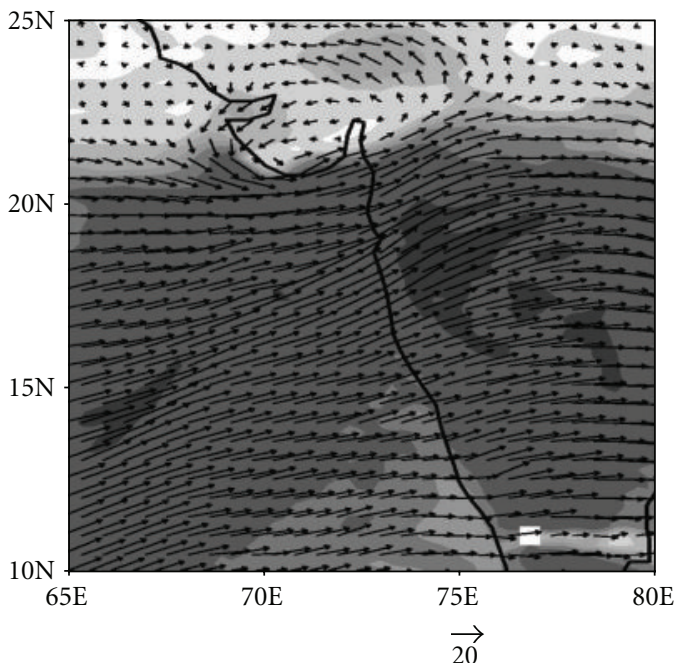

(b)

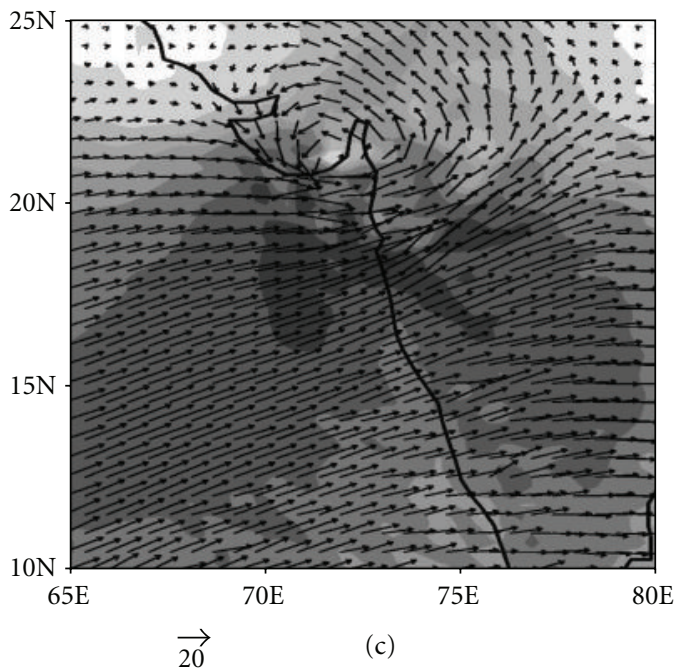

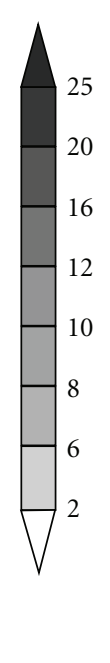
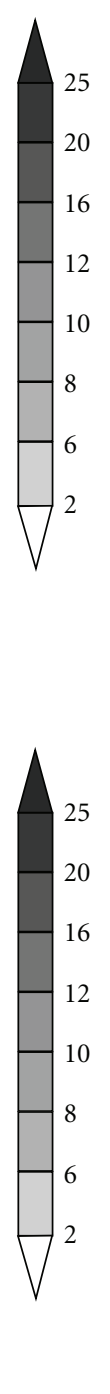

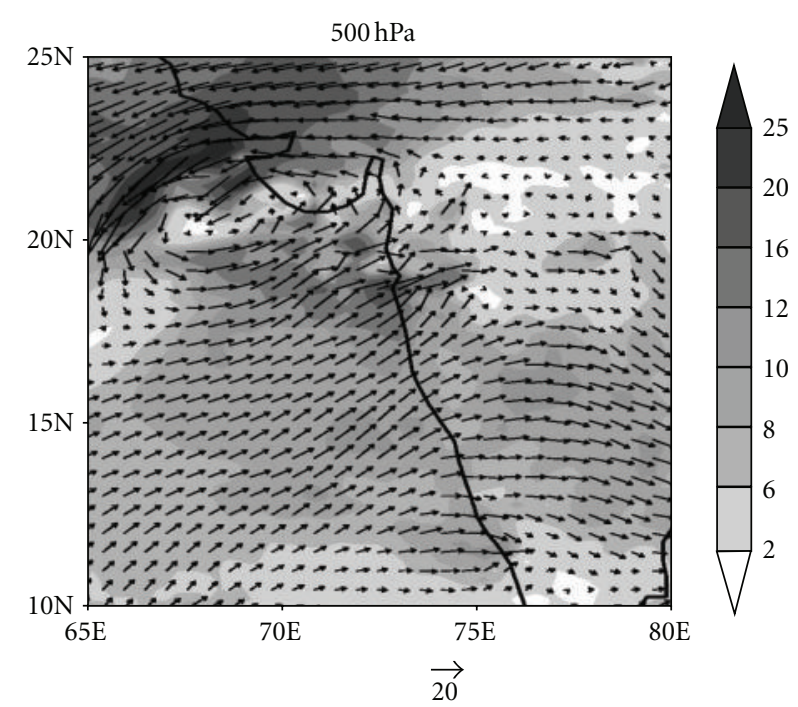

(d)

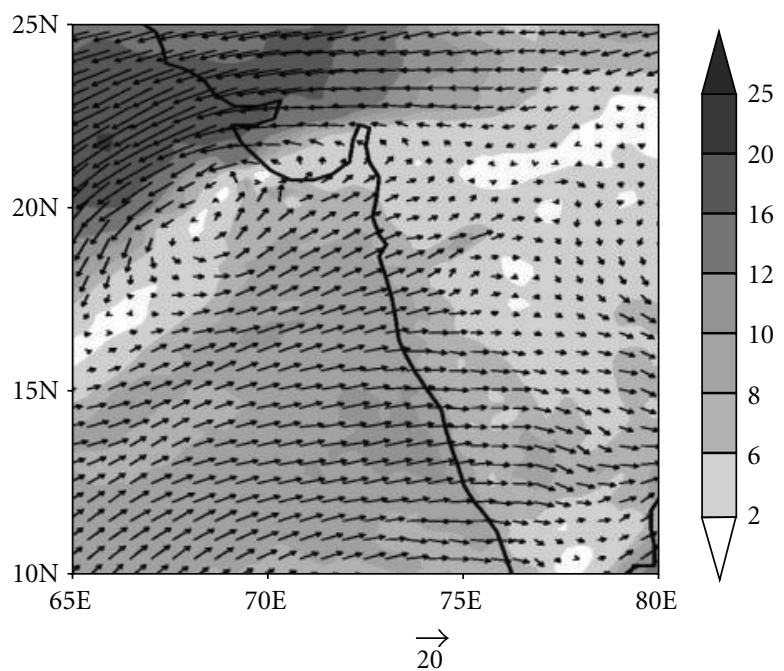

(e)

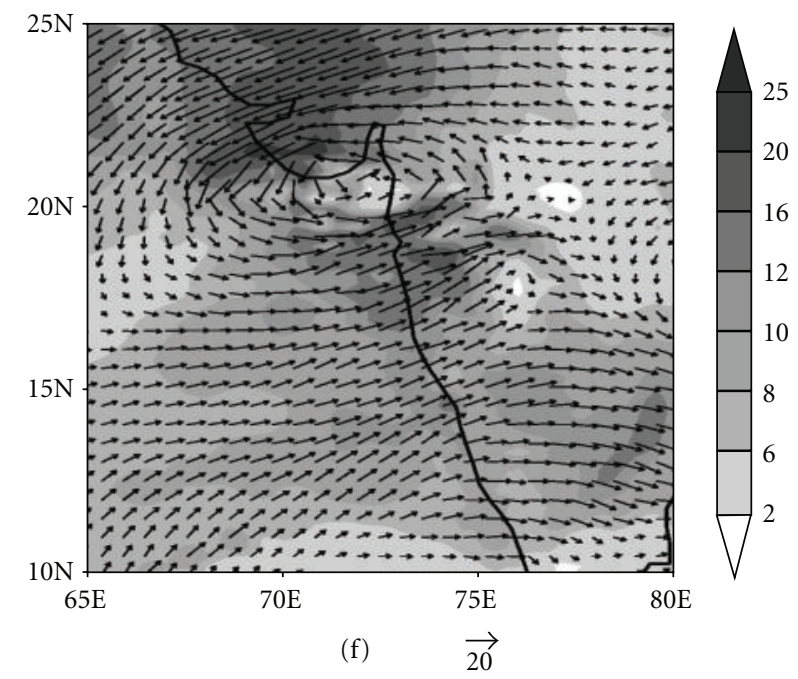

FIgURE 8: (a)-(f): Wind vector and speed (in shaded, $\mathrm{m} \mathrm{s}^{-1}$ ) at 850 hpa for (a) CNTL; (b) NUD and (c) 3DV valid at 0000 UTC on 26 June 2005. (d)-(f) are the same as (a)-(c), respectively, but at pressure level $500 \mathrm{hPa}$. 


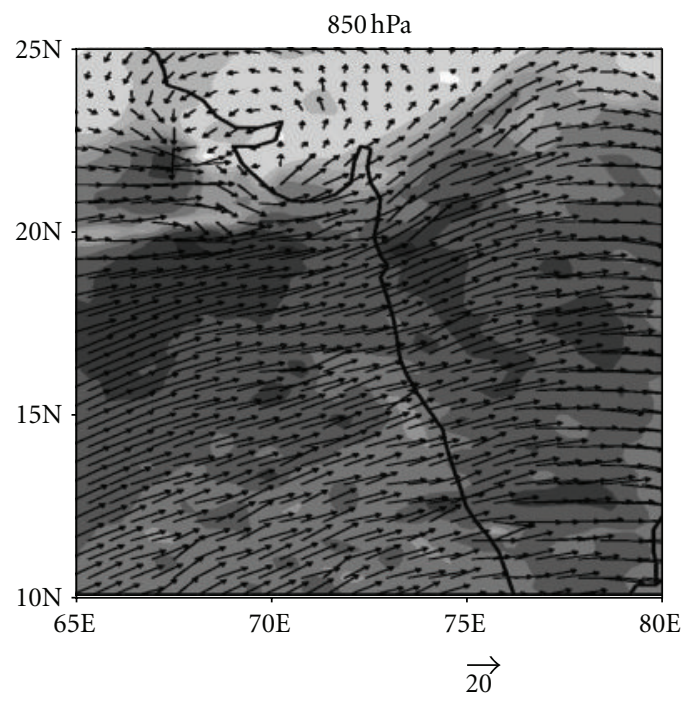

(a)

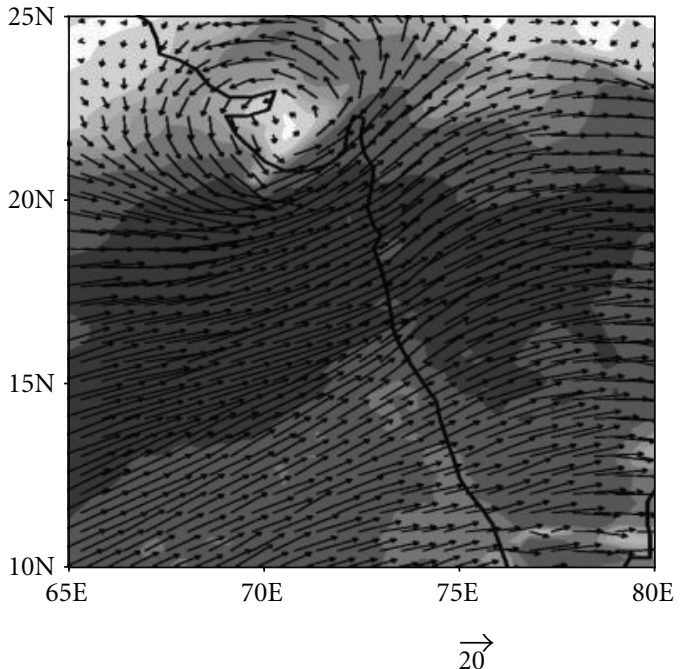

(b)

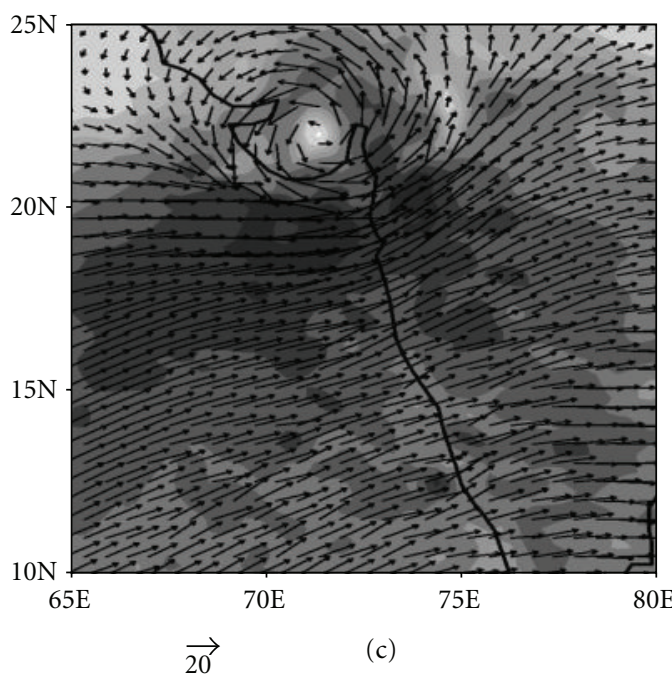

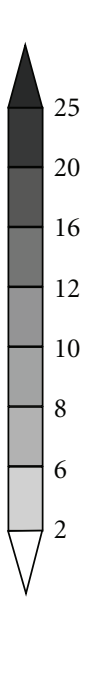
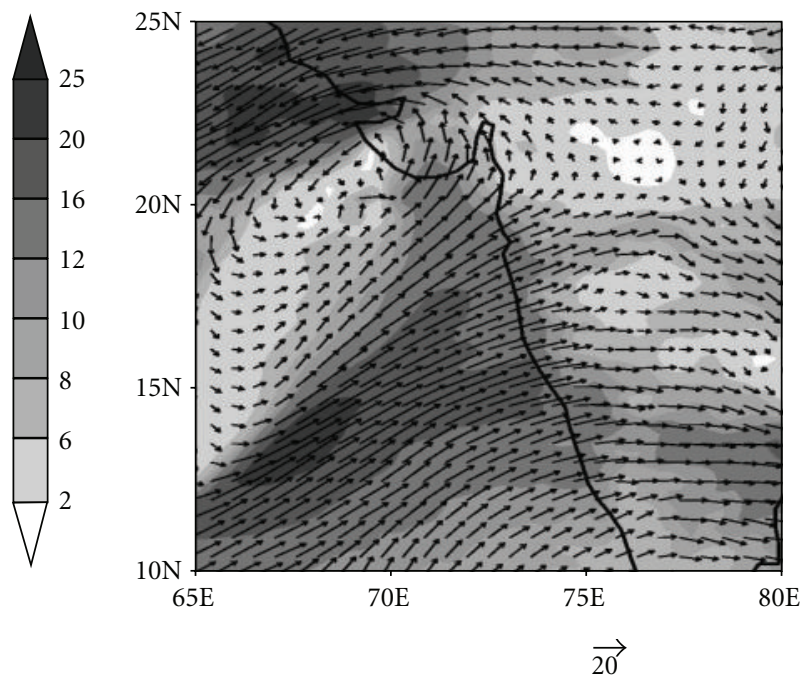

(e)

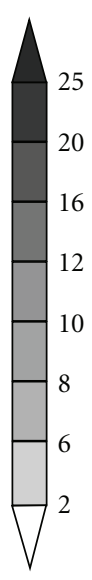

$500 \mathrm{hPa}$

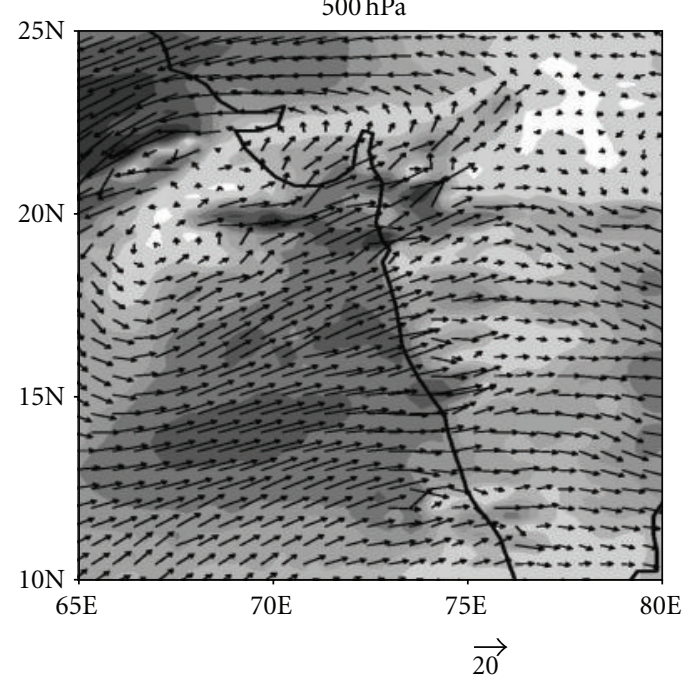

(d)

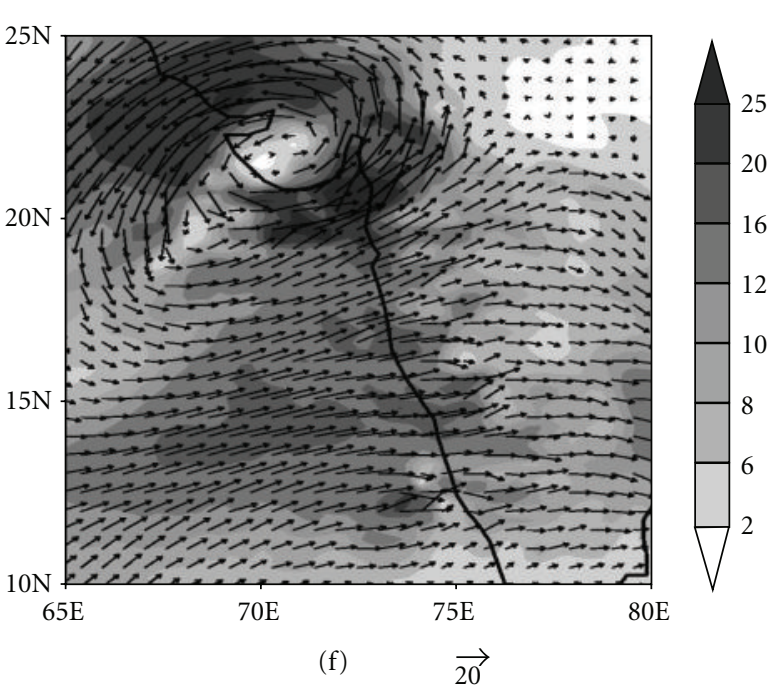

FIGURE 9: (a)-(f) is the same as Figures 8(a)-8(f) but for day 2 valid at 0000 UTC on 27 June 2005. 


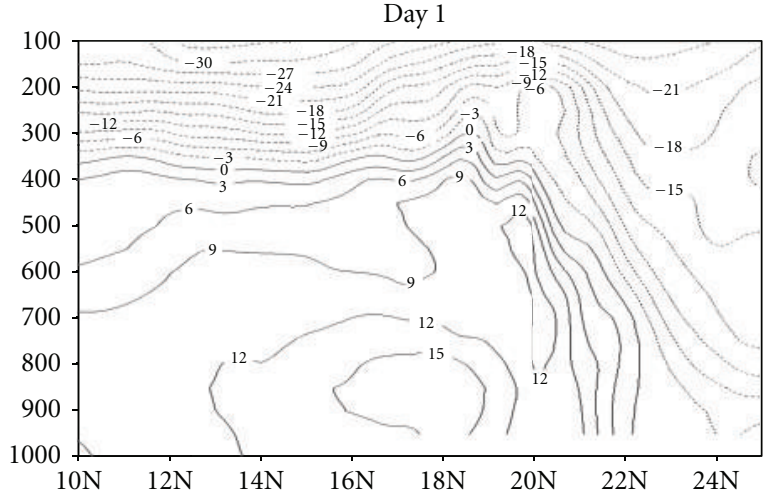

(a)

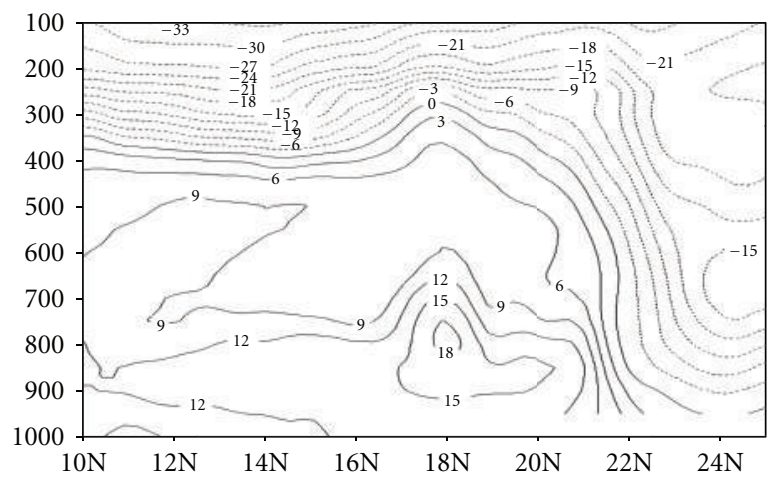

(b)

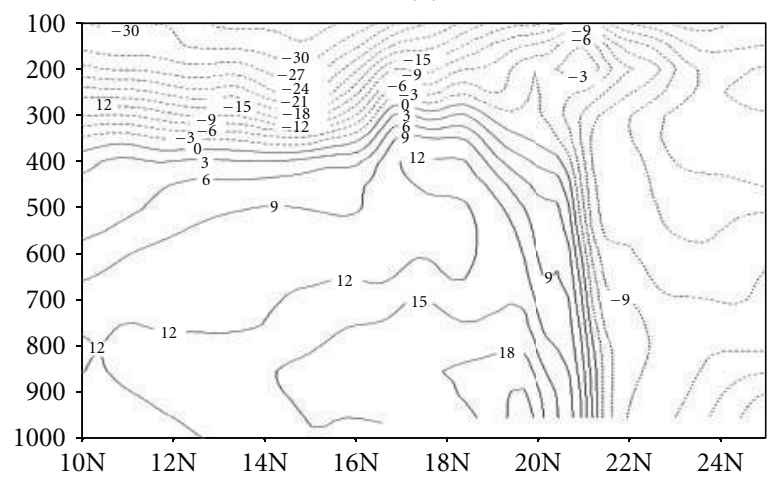

(c)

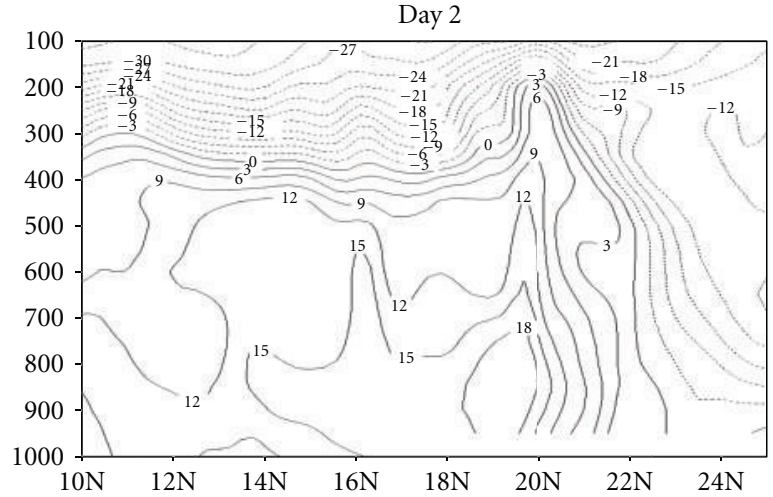

(d)

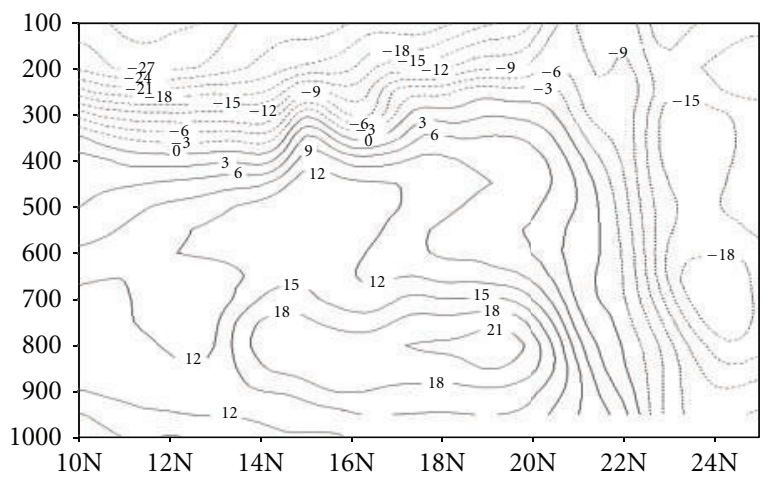

(e)

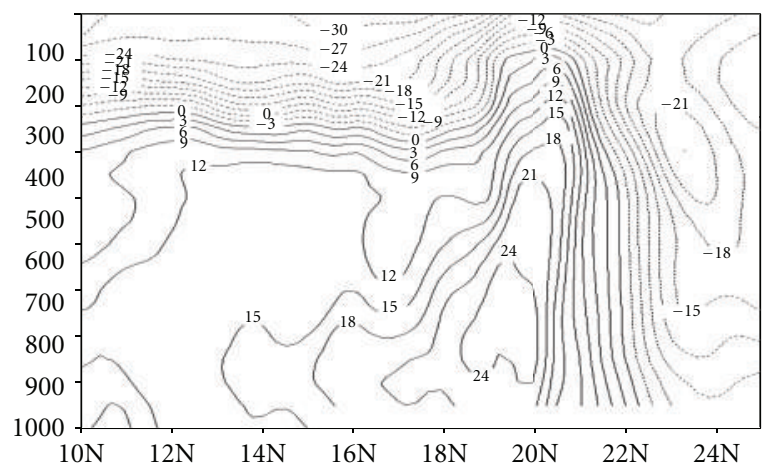

(f)

Figure 10: (a)-(f): Meridional cross-sections of zonal wind ( $u$-component) along longitude $72.0^{\circ} \mathrm{E}$ for (a) CNTL; (b) NUD and (c) 3DV with contour interval $3 \mathrm{~m} \mathrm{~s}^{-1}$ valid at 0000 UTC on 26 June 2005. (d)-(f) are the same as (a)-(c), respectively, but for day 2 valid at 0000 UTC on 27 June 2005 along longitude $70.5^{\circ} \mathrm{E}$.

also improved in the NUD simulations over oceanic region off the west coast of India and a few parts of central India when compared with CNTL. Particularly, the rainfall over the central part of India is shown in only NUD simulations, which is close to the TRMM rainfall pattern over the region. The position of maximum precipitation $(370 \mathrm{~mm})$ recorded at the Gandevi station $\left(20.8^{\circ} \mathrm{N} ; 72.9^{\circ} \mathrm{E}\right)$ and the second maximum rainfall $(200 \mathrm{~mm})$ over Valsad $\left(20.7^{\circ} \mathrm{N} ; 72.9^{\circ} \mathrm{E}\right)$ during day 1 are not captured in the model simulations, but the amount of rainfall is increased significantly with the 3DV simulation over the region (Table 3). Similarly, it is also noticed that the amount of rainfall is also improved over the maximum number of stations with the $3 \mathrm{DV}$ simulation as compared to CNTL and NUD simulation (Table 3 ).

In the day 2 simulation, the MTC over the Saurashtra and Kutch region as well as a zone of strong winds over the Surat region produced several heavy rain bands. The rainfall is also spread offshore over the AS (Figure 11). The TRMM image shows an active zone of precipitation over the Gulf of Kuch $\left(22.5^{\circ} \mathrm{N}, 69.15^{\circ} \mathrm{E}\right)$ and near the Ahmadabad region $\left(23.07^{\circ} \mathrm{N}, 72.63^{\circ} \mathrm{E}\right)$. All the simulations show rainfall south of this region (Figures 11(f)-11(h)). However, the localized distribution of rainfall in the 3DV simulation (Figure 11(h)) is closer to the TRMM and in 

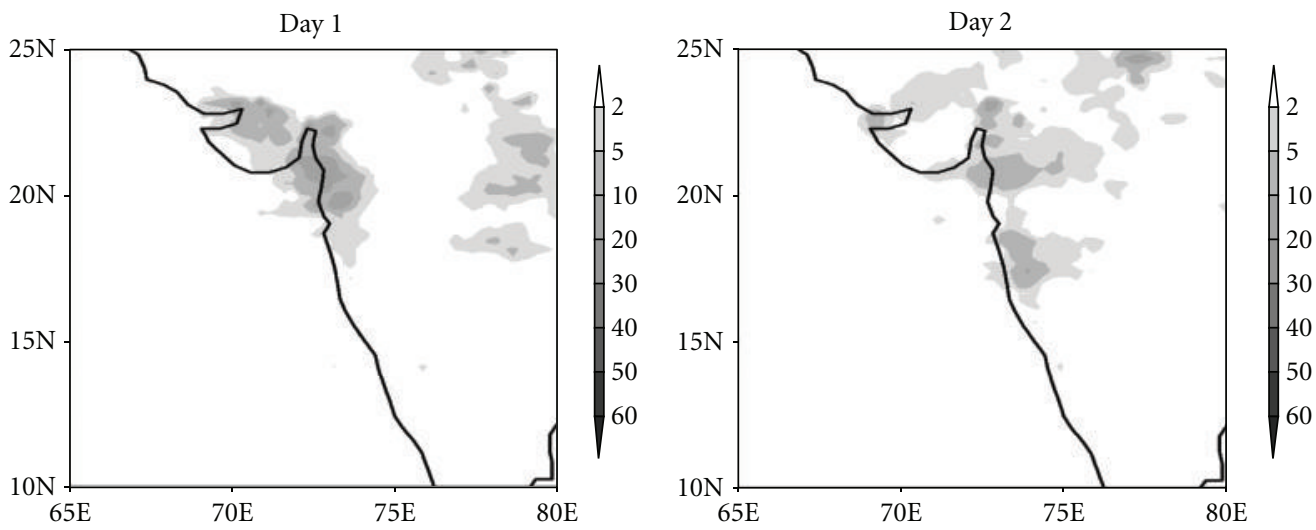

(a)
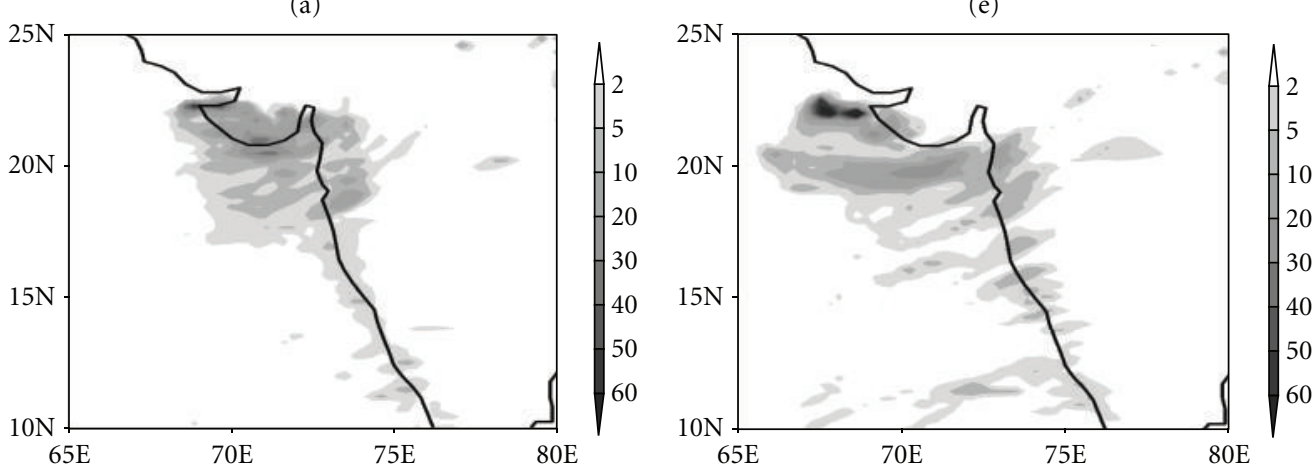

(b)
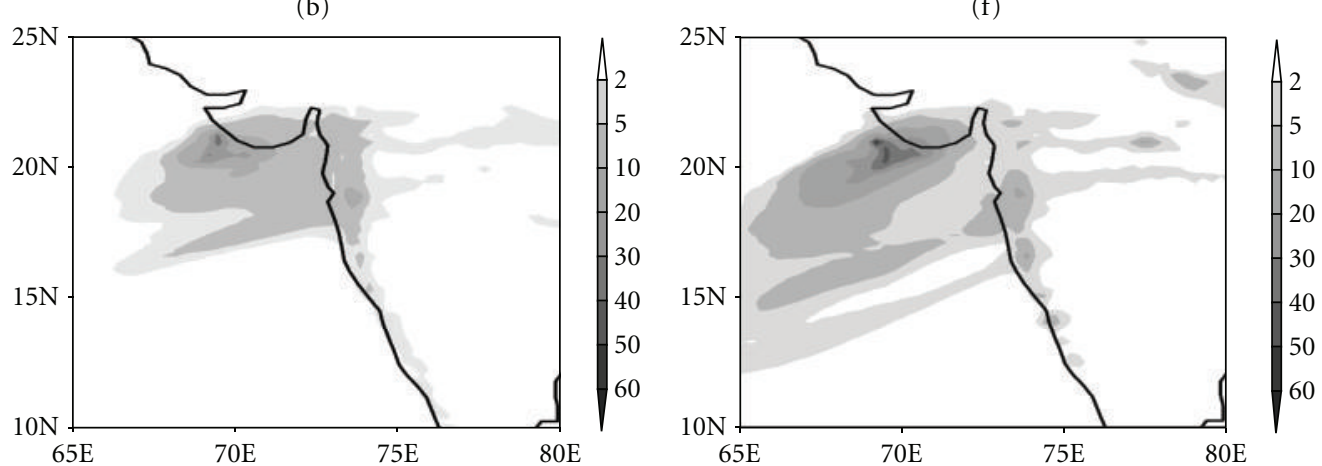

(c)
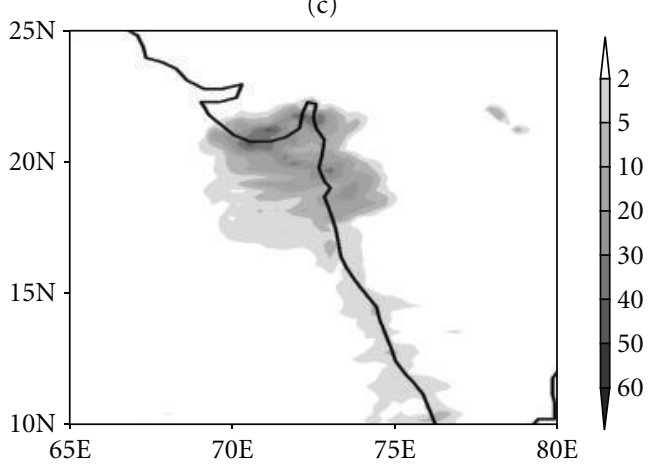

(d)

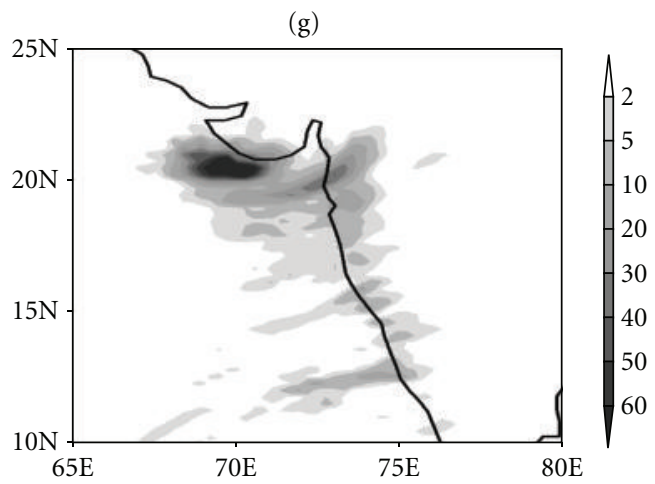

(h)

FIgURE 11: (a)-(h): $24 \mathrm{hrs}$ accumulated precipitations (cm) for (a) TRMM; (b) CNTL; (c) NUD and (d) 3DV valid at 0300 UTC 26 June 2005 (day 1). (e)-(h) are same as (a)-(d), respectively, but valid at 0300 UTC 27 June, 2005 (day 2). 
TABLE 3: Comparison between station-wise observed and model simulated rainfall $(\mathrm{cm})$ for day-1 valid at 0300 UTC of 26 June 2005.

\begin{tabular}{|c|c|c|c|c|c|c|}
\hline \multirow{2}{*}{ Stations } & \multirow{2}{*}{ Lat $(\operatorname{deg} N)$} & \multirow{2}{*}{ Lon $(\operatorname{deg} E)$} & \multicolumn{4}{|c|}{ Day 1} \\
\hline & & & OBS & CNTL & NUD & $3 \mathrm{DV}$ \\
\hline Gandevi & 20.8 & 72.9 & 37 & 9 & 11 & 15 \\
\hline Valsad & 20.7 & 72.9 & 30 & 9 & 10 & 15 \\
\hline Pardi & 20.5 & 72.9 & 21 & 10 & 11 & 15 \\
\hline Chikhli & 21.5 & 73.9 & 20 & 4 & 8 & 12 \\
\hline Bansda & 20.7 & 73.3 & 15 & 5 & 5 & 8 \\
\hline Kamrej & 21.3 & 72.9 & 16 & 7 & 10 & 15 \\
\hline Silvassa & 20.3 & 73.0 & 14 & 6 & 8 & 13 \\
\hline Surat & 21.2 & 72.8 & 17 & 9 & 9 & 15 \\
\hline Dhandhuka & 22.3 & 71.9 & 13 & 3 & 3 & 3 \\
\hline Mangrol & 21.1 & 70.1 & 13 & 10 & 11 & 11 \\
\hline Palsana & 21.1 & 73.0 & 13 & 10 & 11 & 15 \\
\hline Bardoli & 21.1 & 73.1 & 14 & 9 & 12 & 15 \\
\hline Valod & 21.1 & 73.2 & 11 & 11 & 11 & 12 \\
\hline Vapi & 20.4 & 72.9 & 10 & 5 & 7 & 10 \\
\hline Daman & 20.4 & 72.8 & 9 & 5 & 6 & 9 \\
\hline Rajpipla & 21.7 & 73.5 & 9 & 9 & 7 & 9 \\
\hline
\end{tabular}

TABLe 4: The same as Table 3 but for day 2 valid at 0300 UTC of 27 June 2005.

\begin{tabular}{|c|c|c|c|c|c|c|}
\hline \multirow{2}{*}{ Stations } & \multirow{2}{*}{ Latitude $(\operatorname{deg} N)$} & \multirow{2}{*}{ Longitude $(\operatorname{deg} E)$} & \multicolumn{4}{|c|}{ Day 2} \\
\hline & & & OBS & CNTL & NUD & $3 \mathrm{DV}$ \\
\hline Gandevi & 20.8 & 72.9 & 11 & 6 & 10 & 12 \\
\hline Valsad & 20.7 & 72.9 & 13 & 8 & 10 & 12 \\
\hline Pardi & 20.5 & 72.9 & 21 & 14 & 16 & 20 \\
\hline Chikhili & 21.5 & 73.9 & 12 & 4 & 4 & 8 \\
\hline Bansda & 20.7 & 73.3 & 12 & 8 & 8 & 11 \\
\hline Kamrej & 21.3 & 72.9 & 10 & 13 & 15 & 15 \\
\hline Silvassa & 20.3 & 73.0 & 10 & 5 & 6 & 8 \\
\hline Surat & 21.2 & 72.8 & 11 & 8 & 8 & 12 \\
\hline Dhandhuka & 22.3 & 71.9 & 7 & 4 & 4 & 6 \\
\hline Mangrol & 21.1 & 70.1 & 7 & 4 & 5 & 6 \\
\hline Palsana & 21.1 & 73.0 & 5 & 3 & 3 & 4 \\
\hline Bardoli & 21.1 & 73.1 & 8 & 5 & 5 & 6 \\
\hline Valod & 21.1 & 73.2 & 7 & 4 & 6 & 6 \\
\hline Vapi & 20.4 & 72.9 & 9 & 7 & 10 & 12 \\
\hline Daman & 20.4 & 72.8 & 13 & 8 & 8 & 10 \\
\hline Rajpipla & 21.7 & 73.5 & 7 & 4 & 4 & 5 \\
\hline
\end{tabular}

situ rainfall patterns (Figure $1(\mathrm{c})$ ) along the west coast of Gujarat and Maharashtra. But the spatial distribution pattern and amount of rainfall are also relatively increased in the NUD simulation (Figure 11( g)) over these regions compared with CNTL (Figure 11(f)). The observed maximum rainfall $(210 \mathrm{~mm})$ over Pardi station $\left(20.4^{\circ} \mathrm{N}, 72.9^{\circ} \mathrm{E}\right)$ and the second maximum $(130 \mathrm{~mm})$ over Daman $\left(20.4^{\circ} \mathrm{N}, 72.8^{\circ} \mathrm{E}\right)$ and also over Valsad $\left(20.7^{\circ} \mathrm{N}, 72.9^{\circ} \mathrm{E}\right.$ ) during day 2 (Table 4 ) are brought out well in the $3 \mathrm{DV}$ experiment compared to the NUD and CNTL simulations. Table 4 shows that the observed amount of rainfall over the maximum number of stations is close to the $3 \mathrm{DV}$ simulated amount of rainfall.
5.2.3. Vorticity. The vertical cross-section of relative vorticity field along the longitude $72.0^{\circ} \mathrm{E}$ and $70.5^{\circ} \mathrm{E}$ for day 1 and day 2 are shown in Figure 12, respectively. The figures illustrate the structural difference in this relative vorticity field among the simulations obtained from different experiments. In 3DV simulations (Figures 12(c) and 12(f)), the cyclonic vorticity is stronger and the organization shows a positive vorticity (25 to $30 \times 10^{-5} \mathrm{~s}^{-1}$ ) in the lower troposphere (around $900-800 \mathrm{hPa})$ and anticyclonic vorticity $(-15$ to $-20 \times$ $10^{-5} \mathrm{~s}^{-1}$ ) around $300 \mathrm{hPa}$. These stronger vorticity features are not noticed in CNTL (Figures 12(a) and 12(d)) and NUD (Figures 12(b) and 12(e)) simulations. But the vorticity has 
TABLE 5: Spatial correlation coefficients (CC) and RMSE $\left(\mathrm{m} \mathrm{s}^{-1}\right)$ of wind at 850 and $500 \mathrm{hPa}$ between FNL analyses and model simulations from different experiments.

\begin{tabular}{|c|c|c|c|c|c|c|c|c|}
\hline \multirow{3}{*}{ Name of Experiments } & \multicolumn{4}{|c|}{ RMSE } & \multicolumn{4}{|c|}{$\mathrm{CC}$} \\
\hline & \multicolumn{2}{|c|}{$850 \mathrm{hPa}$} & \multicolumn{2}{|c|}{$500 \mathrm{hPa}$} & \multicolumn{2}{|c|}{$850 \mathrm{hPa}$} & \multicolumn{2}{|c|}{$500 \mathrm{hPa}$} \\
\hline & Day 1 & Day 2 & Day 1 & Day 2 & Day 1 & Day 2 & Day 1 & Day 2 \\
\hline CNTL & 6.34 & 6.83 & 5.61 & 6.70 & 0.45 & 0.52 & 0.51 & 0.35 \\
\hline NUD & 5.02 & 4.67 & 4.52 & 4.74 & 0.53 & 0.61 & 0.65 & 0.46 \\
\hline $3 \mathrm{DV}$ & 3.66 & 3.79 & 3.37 & 3.75 & 0.72 & 0.76 & 0.73 & 0.67 \\
\hline
\end{tabular}

TABLe 6: RMSE $\left(\mathrm{m} \mathrm{s}^{-1}\right)$ and CC for zonal $(u)$ and meridional $(v)$ wind components of model simulations with respect to upper-air observation at Mumbai $\left(19.1^{\circ} \mathrm{N}, 72.8^{\circ} \mathrm{E}\right)$ valid at $0000 \mathrm{UTC}$ of 25-27 June 2005.

\begin{tabular}{|c|c|c|c|c|c|c|c|c|c|c|c|c|}
\hline \multirow{3}{*}{ Date (June 2005) } & \multicolumn{6}{|c|}{ RMSE } & \multicolumn{6}{|c|}{$\mathrm{CC}$} \\
\hline & \multicolumn{3}{|c|}{$u\left(\mathrm{~m} \mathrm{~s}^{-1}\right)$} & \multicolumn{3}{|c|}{$v\left(\mathrm{~m} \mathrm{~s}^{-1}\right)$} & \multicolumn{3}{|c|}{$u$} & \multicolumn{3}{|c|}{$v$} \\
\hline & CNTL & NUD & $3 \mathrm{DV}$ & CNTL & NUD & $3 \mathrm{DV}$ & CNTL & NUD & $3 \mathrm{DV}$ & CNTL & NUD & $3 \mathrm{DV}$ \\
\hline 25 & 7.16 & 5.26 & 2.81 & 7.97 & 5.13 & 3.56 & 0.48 & 0.64 & 0.86 & 0.35 & 0.41 & 0.54 \\
\hline 26 & 9.83 & 7.48 & 4.94 & 8.49 & 7.24 & 6.29 & 0.36 & 0.42 & 0.72 & 0.39 & 0.48 & 0.68 \\
\hline 27 & 15.34 & 11.75 & 9.70 & 6.84 & 5.65 & 4.07 & 0.41 & 0.50 & 0.81 & 0.56 & 0.63 & 0.88 \\
\hline
\end{tabular}

reasonably been improved in the NUD simulation except in day 1 simulation compared to CNTL. The 3DV simulations (Figures 12(c) and 12(f)) show strong convergence at midtroposphere and a strong compensating divergence at upper troposphere, which represent the intensity of the MTC. The day 1 and day 2 model simulations also show that the vertical structure along the north-south cross-section of the vorticity over the simulated location of the MTC, where the vorticity maximum is $15 \times 10^{-5} \mathrm{~s}^{-1}$ near $500 \mathrm{hPa}$. This vorticity maximum is reflective of the mesoscale wind shears near the center of the MTC. A weak cyclonic vorticity shows near the surface and anti-cyclonic vorticity is above $400 \mathrm{hPa}$.

5.2.4. Vertical Velocity. It has been known that thermal advection is a primary contributor to the total vertical motion in the vicinity of the mid-level cyclone [19]. The horizontal distribution of vertical motion at $500 \mathrm{hPa}$ for day 1 and day 2 is shown in Figures 13(a)-13(f). The vertical motion field at $500 \mathrm{hPa}$ is reasonably well simulated in all the experiments. However, the largest magnitudes of vertical velocity of the order of 1.5 to $2 \mathrm{~m} \mathrm{~s}^{-1}$ are found in the $3 \mathrm{DV}$ simulations (Figures 13(c) and 13(f)) over the northeastern part of AS and Saurashtra and Kutch regions. But these appear to have physical importance since the regions of rising motion correlate reasonably well with cloud cover during these periods (Figures 1(b) and 1(c)). Similarly, features of the vertical velocity are not observed in CNTL and NUD simulations as compared to $3 \mathrm{DV}$ simulation.

5.2.5. Quantitative Verifications. The feature specific study till now has revealed that the $3 \mathrm{DV}$ simulation is capable of describing the circulation characteristics of the MTC in a better way as compared to the CNTL and NUD simulations. In this section, a quantitative investigation is carried out to asses the impact of the improved analysis. The space correlation coefficient (CC) and root mean square errors
(RMSE) of wind field at 850 and $500 \mathrm{hPa}$ pressure level are calculated for the three model simulations (CNTL, NUD, and $3 \mathrm{DV}$ ) with respect to FNL analysis over a spatial box of $10^{\circ} \times 10^{\circ}$ (latitude: $15-25^{\circ} \mathrm{N}$ and longitude: $67-77^{\circ} \mathrm{E}$ ) for day 1 and day 2 (Table 5). The proposed box is considered around the center of the MTC. The space correlation obtained from 3DV simulation at different pressure levels during day 1 and day 2 is significantly higher as compared with the CNTL and NUD simulations. Table 5 also indicates a significantly lower RMSE of the wind field at different pressure levels for the 3DV simulation as compared to the CNTL and NUD experiments. However, it is also observed that the spatial CC and RMSE are reasonably improved in the NUD simulation than the CNTL.

The vertical profiles of zonal $(u)$ and meridional $(v)$ component of wind are computed at Mumbai $\left(19.1^{\circ} \mathrm{N}\right.$, $72.8^{\circ} \mathrm{E}$ ) observation point from three analyses and model simulations during the period 25-27 June 2005 (figure not provided). At model initial time, the wind components from $3 \mathrm{DV}$ analysis are generally in good agreement with the observed profile compared to the FNL and NUD analyses. This is also reflected in the RMSE and CC values for three analyses against upper-air observations (Table 6). The zonal (meridional) wind component from 3DV analysis shows an improvement from NUD and CNTL of 45-65\% (30$55 \%)$ in RMSE and $35-75 \%(31-54 \%)$ in CC (Table 6). Thus, the 3DV has improved the representativeness of the atmospheric state reasonably well as compared to the FNL and NUD analyses. The 3DVAR data assimilation system is able to successfully establish the mesoconvective activity embedded in the large-scale convection as initial condition for model simulation. During day 1, the upperlevel $(200 \mathrm{hPa}) u$-component of wind is not well represented by the three simulations though the low level zonal wind component from the $3 \mathrm{DV}$ simulation is in better agreement with the observations compared to the CNTL and NUD. For day 2, the wind components in the 3DV experiment 

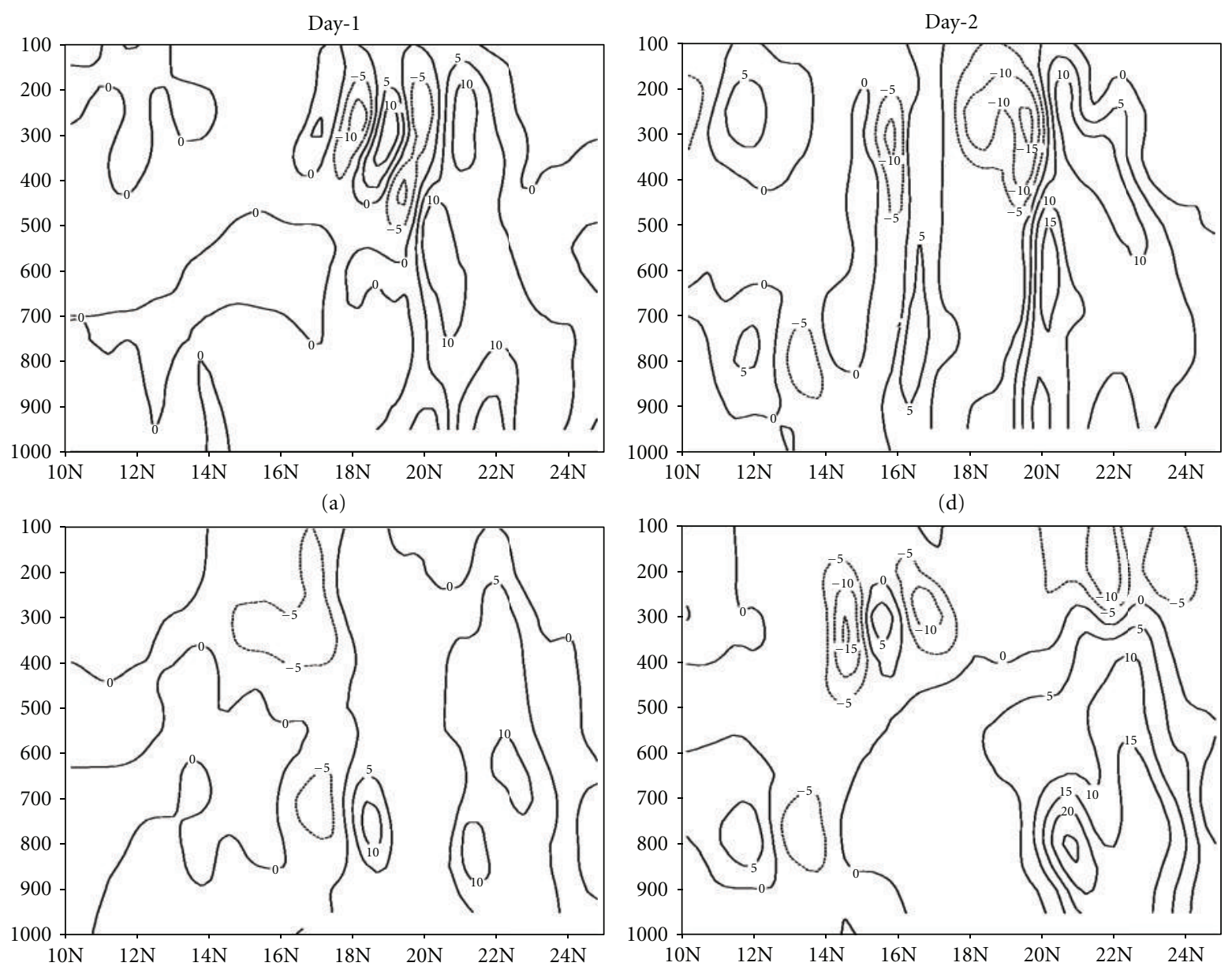

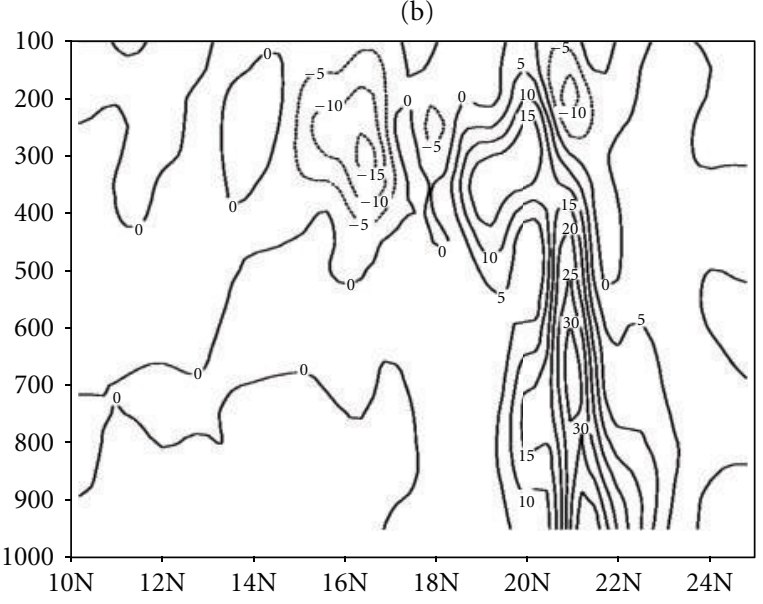

(c)

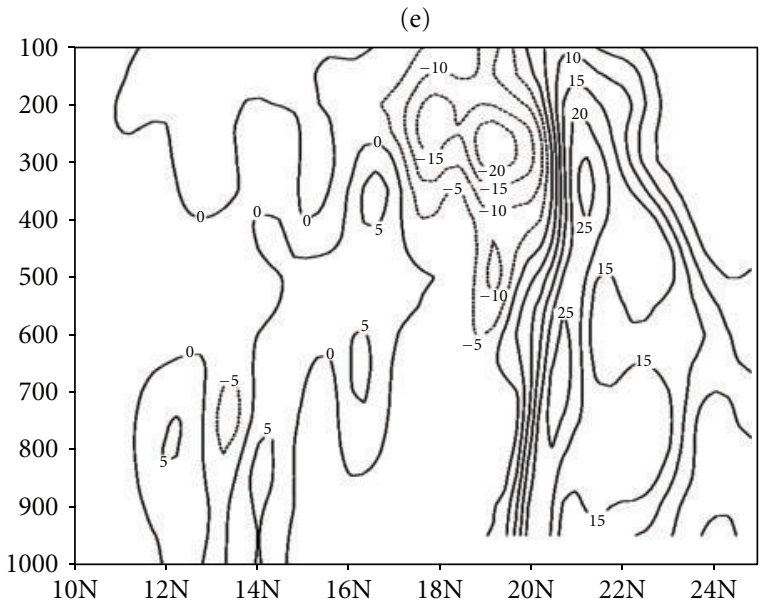

(f)

Figure 12: (a)-(f): Meridional cross-section of vorticity (interval $5 \times 10^{-5} \mathrm{~s}^{-1}$ ) along longitude $72.0^{\circ} \mathrm{E}$ for (a) CNTL; (b) NUD and (c) 3DV valid at 0000 UTC on 26 June 2005 (day 1). (d)-(f) are the same as (a)-(c), respectively, but for day 2 valid at 0000 UTC on 27 June 2005 along longitude $70.5^{\circ} \mathrm{E}$. 
Day 1
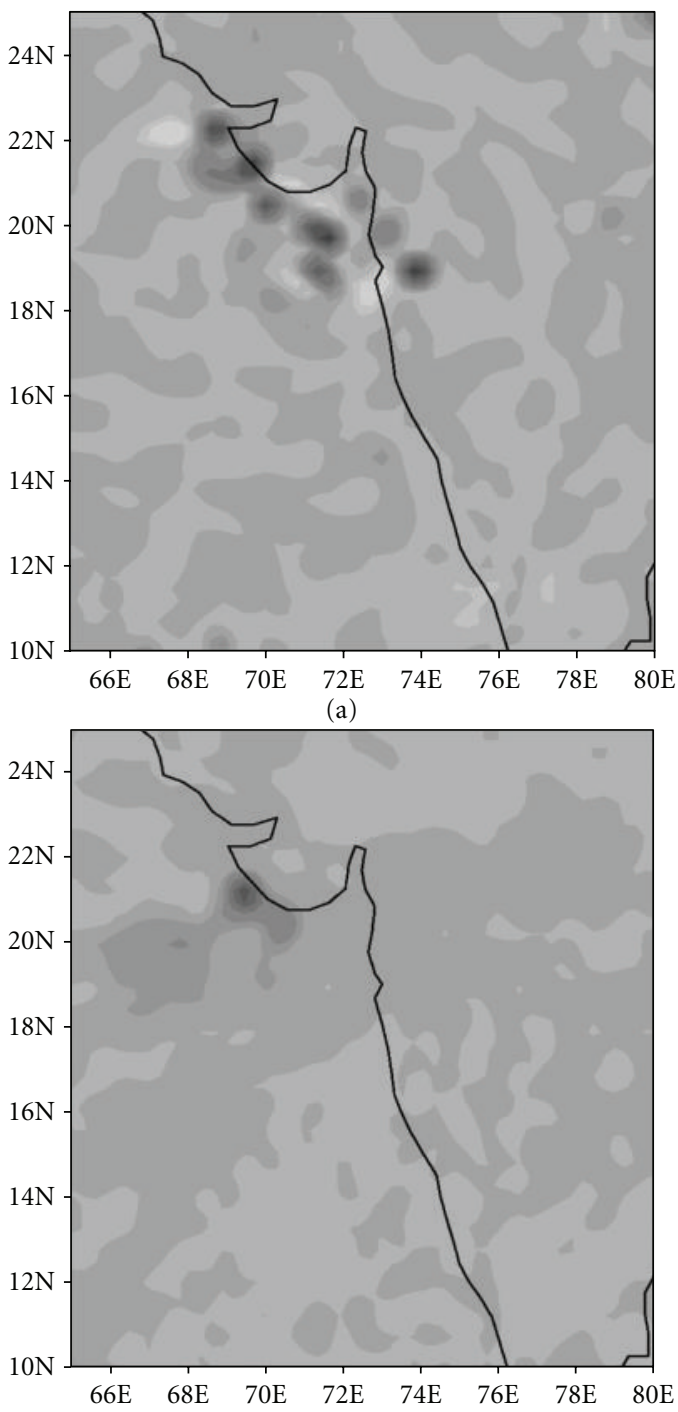

(b)

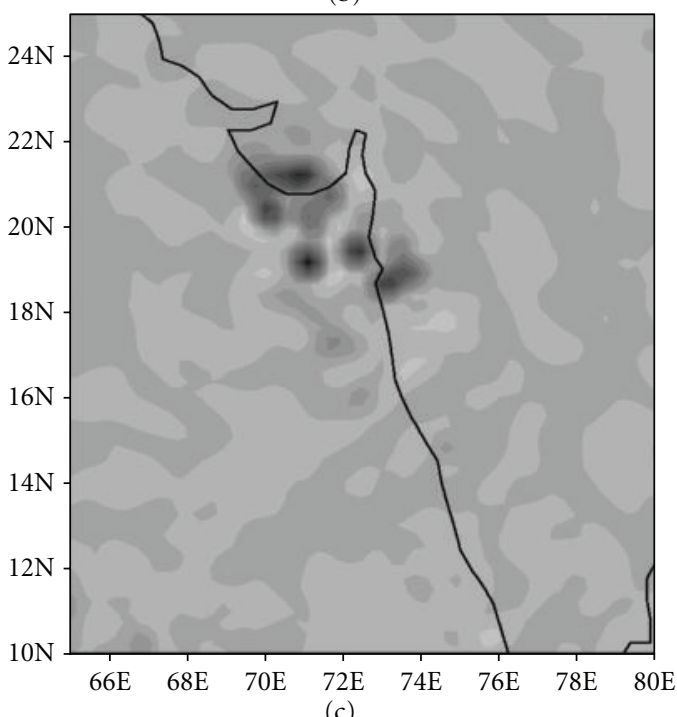

Day 2
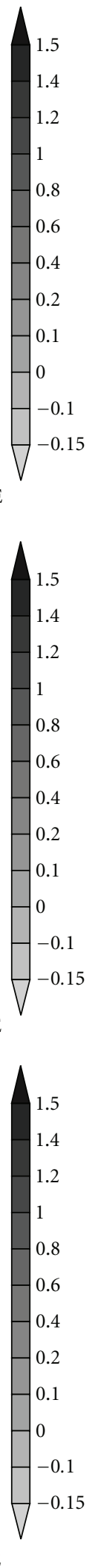

(d)
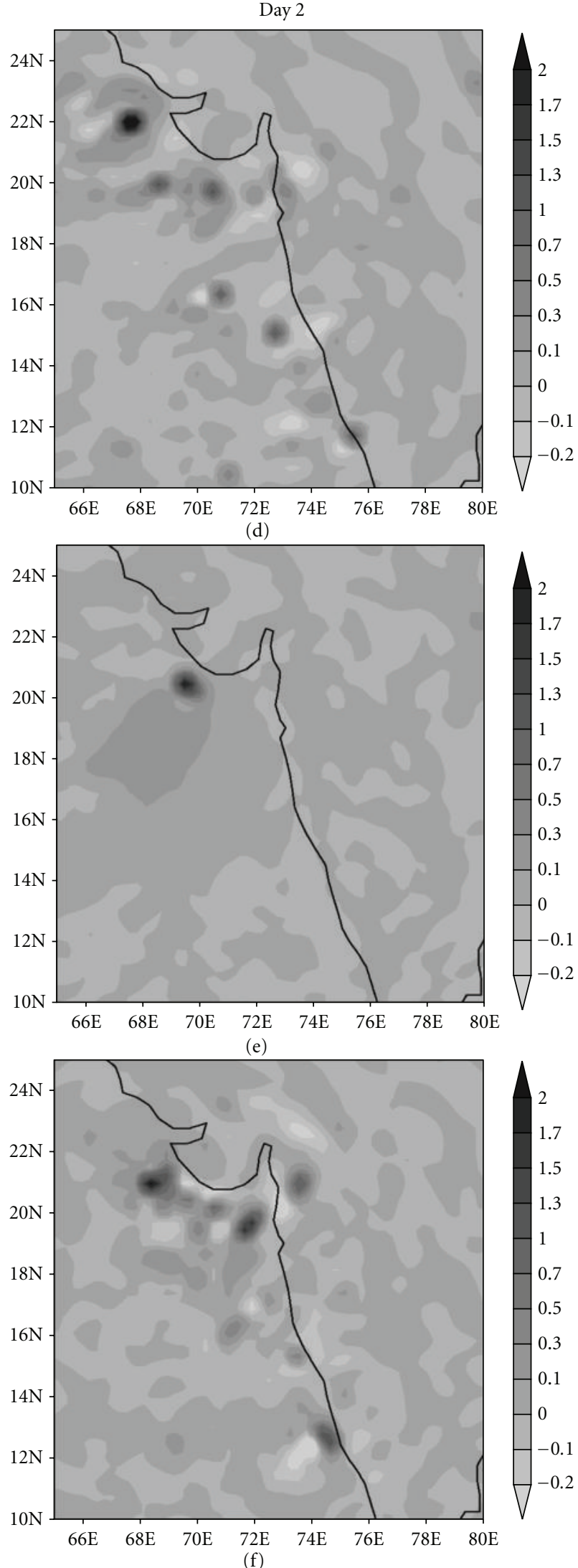

Figure 13: (a)-(f): Vertical velocity $\left(\mathrm{m} \mathrm{s}^{-1}\right)$ at $500 \mathrm{hPa}$ for (a) CNTL; (b) NUD and (c) 3DV valid at 0000 UTC on 26 June 2005. (d)-(f) are the same as (a)-(c), respectively, but for day 2 valid at 0000 UTC on 27 June 2005. 


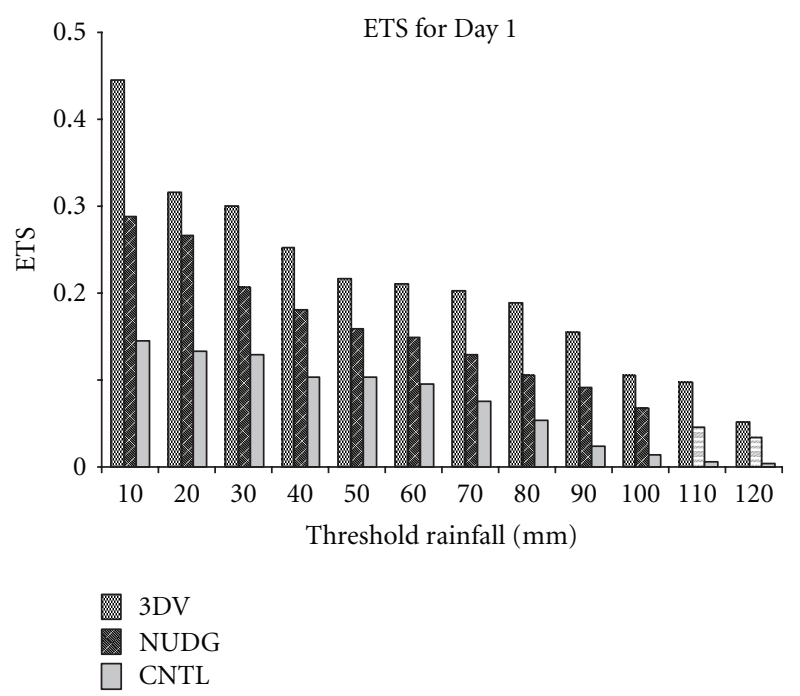

(a)

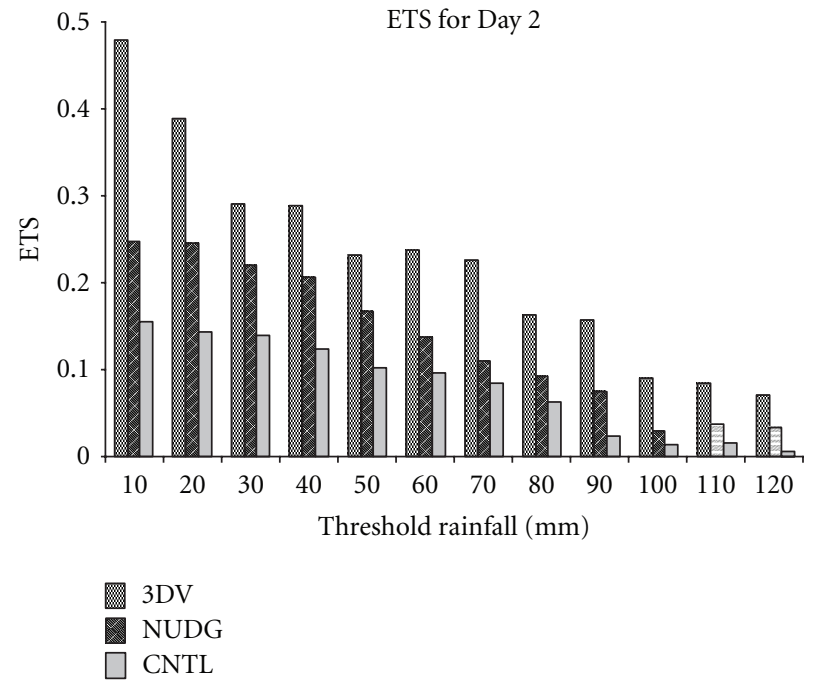

(b)

Figure 14: Equitable Threat Scores (ETS) of rainfall with different threshold (mm) from experiments CNTL, NUD, and 3DV for (a) day 1 and (b) day 2.

followed similar trend with the observations compared to CNTL and NUD simulations. This is reflected in the RMSE and CC parameters summarized in Table 6. The wind fields are significantly improved after assimilation of Indian conventional and nonconventional observations.

Using the TRMM rainfall observations, Equitable Threat Scores (ETS) are calculated for the rainfall forecasts. The ETS is widely used to measure precipitation forecast skill. It is defined as

$$
\mathrm{ETS}=\frac{(\mathrm{CFA}-\mathrm{CHA})}{(F+O-\mathrm{CFA}-\mathrm{CHA})}, \quad \mathrm{CHA}=O \frac{F}{V} .
$$

In the above equations, each variable indicates the number of grid points at which (i) rainfall is correctly forecasted to exceed the specified threshold (CFA), (ii) rainfall is forecasted to exceed the threshold $(F)$, (iii) rainfall is observed to exceed the threshold $(O)$, and (iv) a correct forecast would occur by chance (CHA), where $V$ is the total number of evaluated grid points. The ETS range is from 0 to 1 , with a value of 1 indicating a perfect forecast. The details of the formulation of this skill score can be found in the study by [20]. Figures 14(a) and 14(b) illustrated the ETS of rainfall during day 1 and day 2 with different threshold values in (mm) for experiments 3DV, NUD, and CNTL, respectively. Rainfall verification is performed using the TRMM derived rainfall data as the observation. The results clearly indicate that the assimilation experiment (3DV) shows maximum ETS rather than the other two experiments during day 1 and day 2. The ETS values have also been improved in the NUD experiment as compared to CNTL experiment.

It would be of interest to analyze the spatial (latitude: $15-25^{\circ} \mathrm{N}$ and longitude: $67-77^{\circ} \mathrm{E}$ ) correlation and RMSE of rainfall between TRMM and the model simulations from the three numerical experiments for day 1 and day 2 (Table 7). Though CC are not very large in all experiments, it can be easily noted that the $3 \mathrm{DV}$ can estimate the rainfall pattern better than the other two experiments. The rainfall estimated for day 1 is showing better spatial distribution than that estimated for day 2. On day 2, the model simulations have shown that the rainfall is mainly concentrated over the west coast of India and AS but TRMM is showing that rainfall has occurred more over the land. Due to this contrast distribution of rainfall, the spatial correlation values on day 2 have been reduced. The spatial correlation values are also improved in the NUD experiment as compared with the CNTL experiment in all days (Table 7).

\section{Conclusions}

A mesoscale model (WRF-ARW, version 3.0) with a single domain at a $30 \mathrm{~km}$ horizontal resolution has been used to simulate heavy rainfall event over the western Indian region during the occurrence of MTC. For this, an attempt has been made to carry out a comparative study between the analysis nudging and 3DVAR data assimilation system for the simulation of heavy rainfall event during 25-28 June 2005 along the west coast of India. Based on the results presented in the previous sections, the following broad conclusions are arrived.

Comparing the results obtained from the global FNL, NUD, and 3DVAR analyses, the 3DVAR data assimilation technique substantially improved the overall simulation over the Indian monsoon region. After successful insertion of conventional and nonconventional observation data, the analyzed data with increased horizontal resolution produced the desired deep convective signatures of the specified weather event consistent with the large-scale flow.

The 3DV simulation represented well the location and intensity of the MTC as compared to NUD and CNTL simulations. This enhancement in the MTC simulation is 
TABLE 7: Spatial CC and RMSE (mm) of rainfall between TRMM and model simulations from different experiments.

\begin{tabular}{lcccc}
\hline \multirow{2}{*}{ Experiment Name } & \multicolumn{2}{c}{ RMSE } & \multicolumn{2}{c}{ CC } \\
& Day 1 & Day 2 & Day 1 & Day 2 \\
\hline CNTL & 26.45 & 24.85 & 0.28 & 0.21 \\
NUD & 21.64 & 18.85 & 0.42 & 0.34 \\
3DV & 18.20 & 12.80 & 0.78 & 0.63 \\
\hline
\end{tabular}

a clear depiction of the impact of additional observation data. The assimilation experiment produced strong vertical updraft at different pressure levels near the region where the horizontal convergence occurs as compared to CNTL experiment. The spatial correlations and RMSE of wind field at different pressure levels are significantly improved in the assimilation experiments mainly on 3DV simulation as compared to NUD and CNTL simulations.

The 3DV experiment is able to capture the location and amount of rainfall over the west coast of India reasonably well rather than CNTL and NUD simulations. However, the rainfall distribution also improved in the NUD experiment as compared to CNTL. Further improvement can be obtained by improving the model horizontal resolution, physical parameterizations such as land surface representation [21] and also inserting additional high-resolution Doppler Weather Radar (DWR) data and high quality dense network surface and upper-air observation data [11].

The statistical skill scores also revealed that the precipitation forecast during day 1 and day 2 is significantly improved in the 3DV experiment as compared to CNTL and NUD experiments.

\section{Acknowledgments}

The authors acknowledge the NCEP for providing the FNL analysis data sets for the present study. The authors also owe their thanks to the IMD for providing the surface and upper-air observations, which have been used in the 3DVAR data assimilation system for this study. Thanks also to Dr. Dale Barker and Dr. Syed Rizvi, MMM Division, NCAR, for their assistance with this study. They sincerely thank the anonymous reviewers for their valuable and constructive comments/suggestions to the further improvement of the paper.

\section{References}

[1] T. N. Krishnamurti, S. Cocke, R. Pasch, and S. Low-Nam, Precipitation Estimates from Rain Gauge and Satellite Observations: Summer MONEX, Department of Meteorology, Florida State University, 1983.

[2] L. F. Bosart and F. H. Carr, "A case study of excessive rainfall centered around Wellsville, New York, 20-21 June 1972," Monthly Weather Review, vol. 106, no. 3, pp. 348-362, 1978.

[3] B. E. Schwartz, C. F. Chappell, W. E. Togstad, and X. P. Zong, "The Minneapolis flash flood: meteorological analysis and operational response," Weather and Forecasting, vol. 5, no. 1, pp. 3-21, 1990.
[4] S. K. R. Bhowmik and K. Prasad, "Some characteristics of limited-area model-precipitation forecast of Indian monsoon and evaluation of associated flow features," Meteorology and Atmospheric Physics, vol. 76, no. 3-4, pp. 223-236, 2001.

[5] A. Routray, U. C. Mohanty, A. K. Das, and N. V. Sam, "Study of heavy rainfall event over the West-coast of India using analysis nudging in MM5 during ARMEX-I," Mausam, vol. 56, pp. 107-120, 2005.

[6] A. J. Litta, B. Chakrapani, and K. Mohankumar, "Mesoscale simulation of an extreme rainfall event over Mumbai, India, using a high-resolution MM5 model," Meteorological Applications, vol. 14, no. 3, pp. 291-295, 2007.

[7] R. A. Pielke Sr., T. Matsui, G. Leoncini et al., "A new paradigm for parameterizations in numerical weather prediction and other atmospheric models," National Weather Digest, vol. 30, pp. 93-99, 2006.

[8] R. Daley, Atmospheric Data Analysis, Cambridge Atmospheric and Space Science Series, Cambridge University Press, New York, NY, USA, 1991.

[9] H. R. Hatwar, Y. V. Rama Rao, S. K. Roy Bhowmik, D. Joardar, and Geeta Agnihotri, "An impact of ARMEX data on limited area model analysis and forecast system of India Meteorological Department-a preliminary study," Mausam, vol. 56, pp. 131-138, 2005.

[10] V. F. Xavier, A. Chandrasekar, H. Rahman, D. Niyogi, and K. Alapaty, "The effect of satellite and conventional meteorological data assimilation on the mesoscale modeling of monsoon depressions over India," Meteorology and Atmospheric Physics, vol. 101, no. 1-2, pp. 65-92, 2008.

[11] A. Routray, U. C. Mohanty, S. R. H. Rizvi, D. Niyogi, K. K. Osuri, and D. Pradhan, "Impact of Doppler weather radar data on numerical forecast of Indian monsoon depressions," Quarterly Journal of the Royal Meteorological Society, vol. 136, no. 652, pp. 1836-1850, 2010.

[12] M. Das Gupta, J. P. George, and S. Das, "Performance of MM53DVAR system over Indian Subcontinent," in International Conference on "MONEX and Its Legacy", New Delhi, India, February 2005.

[13] J. Dudhia, "The weather research and forecasting model (version 2.0)," in Proceedings of the 2nd International Workshop on Next Generation NWP Model, pp. 19-23, Yonsei University, Seoul, Korea, 2004.

[14] W. C. Skamaraock, J. B. Klemp, Jimmy Dudhia et al., "A description of the advanced research WRF version 2," NCAR Technical Note, 2005.

[15] D. M. Barker, W. Huang, Y. R. Guo, A. Bourgeois, and X. N. Xiao, "A three-dimensional variational data assimilation system for MM5: implementation and initial results," Monthly Weather Review, vol. 132, pp. 897-914, 2004.

[16] D. R. Stauffer and N. L. Seaman, "Use of four-dimensional data assimilation in a limited-area mesoscale model. Part I: experiments with synoptic-scale data," Monthly Weather Review, vol. 118, no. 6, pp. 1250-1277, 1990.

[17] A. Deng, D. R. Stauffer, J. Dudhia, T. Otte, and G. K. Hunter, "Update on Analysis Nudging FDDA in WRF-ARW," in Proceedings of the 8th WRF Users' Workshop, NCAR, Boulder, Colo, USA, June 2007.

[18] R. N. Keshavamurty and M. S. Rao, The Physics of Monsoons, Allied Publishers, New Delhi, India, 1992.

[19] T. N. Krishnamurti and R. S. Hawkins, "Mid-tropospheric cyclones of the Southwest monsoon," Journal of Applied Meteorology, vol. 9, no. 3, pp. 442-458, 1970.

[20] I. Jankov, W. A. Gallus Jr., M. Segal, B. Shaw, and S. E. Koch, "The impact of different WRF model physical 
parameterizations and their interactions on warm season MCS rainfall," Weather and Forecasting, vol. 20, no. 6, pp. 10481060, 2005.

[21] H. I. Chang, A. Kumar, D. Niyogi, U. C. Mohanty, F. Chen, and J. Dudhia, "The role of land surface processes on the mesoscale simulation of the July 26, 2005 heavy rain event over Mumbai, India," Global and Planetary Change, vol. 67, no. 1-2, pp. 87103, 2009. 

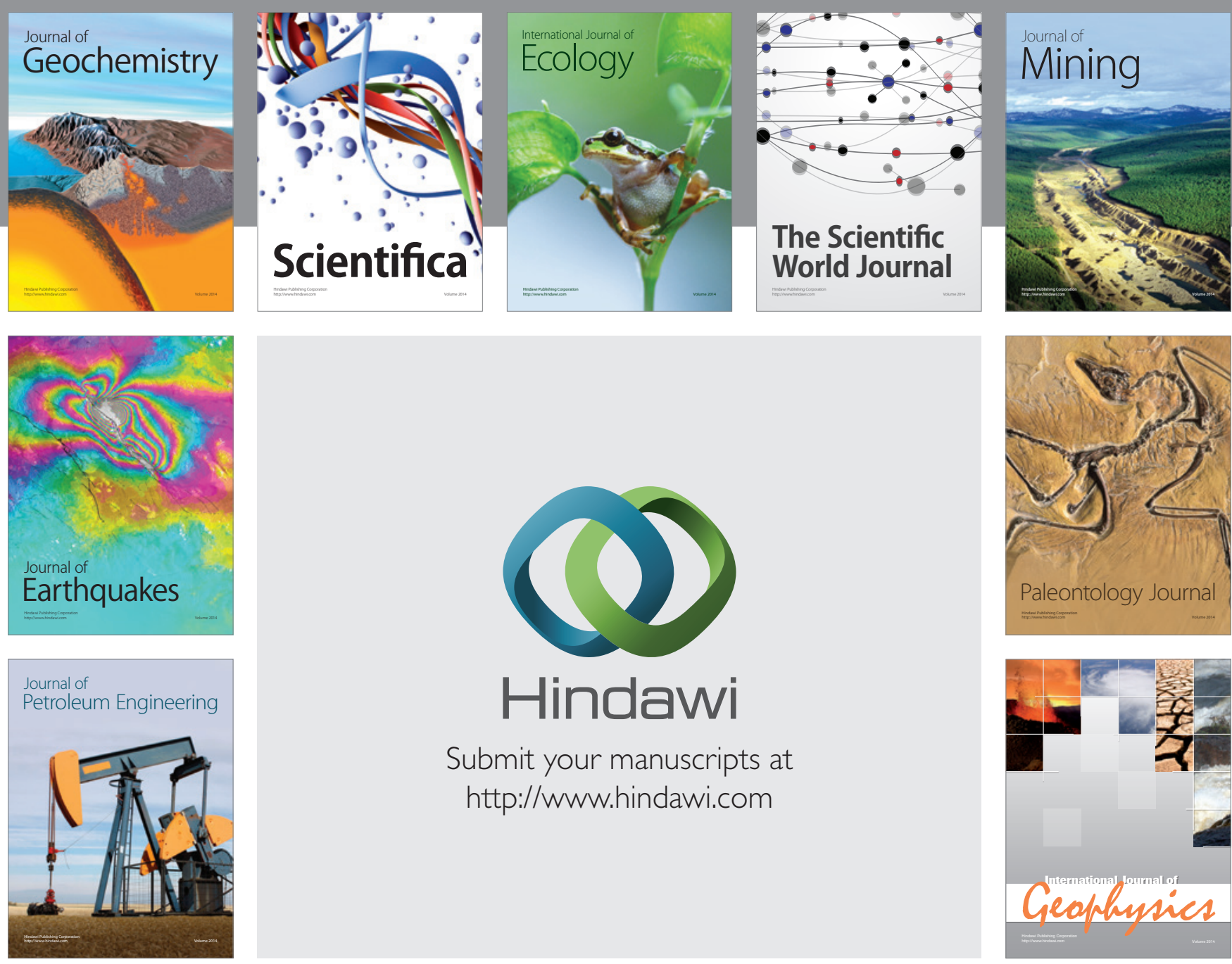

Submit your manuscripts at

http://www.hindawi.com
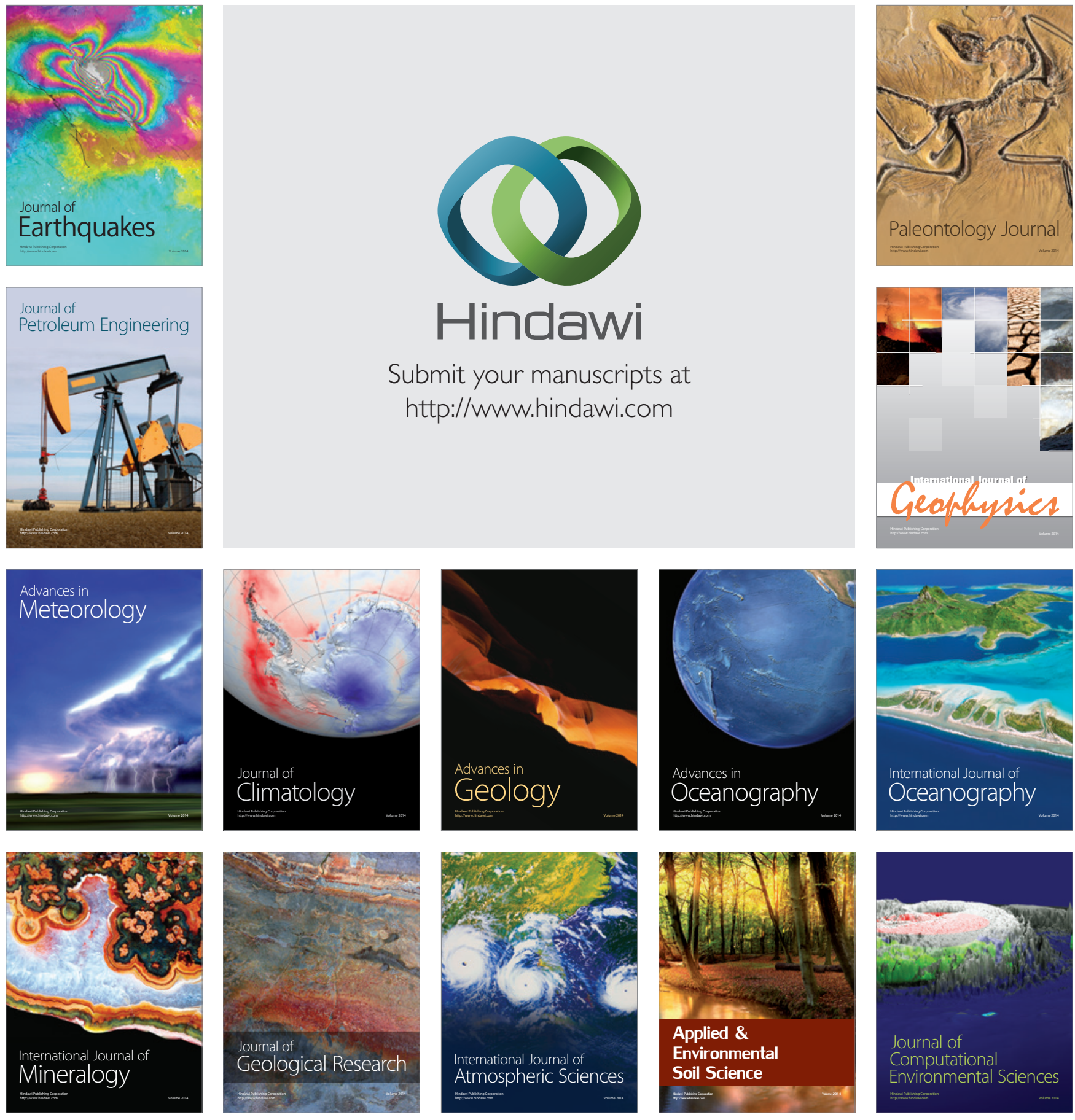